\title{
Analyzing the genomic and transcriptomic architecture of milk traits in Murciano- Granadina goats
}

Dailu Guan ${ }^{1}$, Vincenzo Landi ${ }^{2}$, María Gracia Luigi-Sierra', Juan Vicente Delgado², Xavier Such ${ }^{3}$, Anna Castelló ${ }^{1,3}$, Betlem Cabrera 1,3, Emilio Mármol-Sánchez ${ }^{1}$, Javier Fernández-Alvarez ${ }^{4}$, José Luis Ruiz de la Torre Casañas" Amparo Martínez ${ }^{2}$, Jordi Jordana ${ }^{3}$ and Marcel Amills ${ }^{1,3^{*}}$ (D)

\begin{abstract}
Background: In this study, we aimed to investigate the molecular basis of lactation as well as to identify the genetic factors that influence milk yield and composition in goats. To achieve these two goals, we have analyzed how the mRNA profile of the mammary gland changes in seven Murciano-Granadina goats at each of three different time points, i.e. $78 \mathrm{~d}$ (T1, early lactation), $216 \mathrm{~d}$ (T2, late lactation) and $285 \mathrm{~d}$ (T3, dry period) after parturition. Moreover, we have performed a genome-wide association study (GWAS) for seven dairy traits recorded in the 1st lactation of 822 Murciano-Granadina goats.

Results: The expression profiles of the mammary gland in the early ( $\mathrm{T} 1$ ) and late (T2) lactation were quite similar (42 differentially expressed genes), while strong transcriptomic differences (more than one thousand differentially expressed genes) were observed between the lactating (T1/T2) and non-lactating (T3) mammary glands. A large number of differentially expressed genes were involved in pathways related with the biosynthesis of amino acids, cholesterol, triglycerides and steroids as well as with glycerophospholipid metabolism, adipocytokine signaling, lipid binding, regulation of ion transmembrane transport, calcium ion binding, metalloendopeptidase activity and complement and coagulation cascades. With regard to the second goal of the study, the performance of the GWAS allowed us to detect 24 quantitative trait loci (QTLs), including three genome-wide significant associations: QTL1 (chromosome 2, 130.72-131.01 Mb) for lactose percentage, QTL6 (chromosome 6, 78.90-93.48 Mb) for protein percentage and QTL17 (chromosome 17, $11.20 \mathrm{Mb}$ ) for both protein and dry matter percentages. Interestingly, QTL6 shows positional coincidence with the casein genes, which encode $80 \%$ of milk proteins.

Conclusions: The abrogation of lactation involves dramatic changes in the expression of genes participating in a broad array of physiological processes such as protein, lipid and carbohydrate metabolism, calcium homeostasis, cell death and tissue remodeling, as well as immunity. We also conclude that genetic variation at the casein genes has a major impact on the milk protein content of Murciano-Granadina goats.
\end{abstract}

Keywords: Casein genes, Dairy traits, GWAS, Lactation, QTLs, RNA-Seq

\footnotetext{
* Correspondence: marcel.amills@uab.cat

${ }^{1}$ Centre for Research in Agricultural Genomics (CRAG), CSIC-IRTA-UAB-UB,

Universitat Autònoma de Barcelona, 08193 Bellaterra, Spain

${ }^{3}$ Departament de Ciència Animal i dels Aliments, Facultat de Veterinària,

Universitat Autònoma de Barcelona, 08193 Bellaterra, Spain

Full list of author information is available at the end of the article
}

(c) The Author(s). 2020 Open Access This article is distributed under the terms of the Creative Commons Attribution 4.0 International License (http://creativecommons.org/licenses/by/4.0/), which permits unrestricted use, distribution, and reproduction in any medium, provided you give appropriate credit to the original author(s) and the source, provide a link to the Creative Commons license, and indicate if changes were made. The Creative Commons Public Domain Dedication waiver (http://creativecommons.org/publicdomain/zero/1.0/) applies to the data made available in this article, unless otherwise stated. 


\section{Background}

Understanding how genetic variation shapes the phenotypic diversity of milk traits not only implies the identification of such genetic determinants through genome-wide association studies (GWAS), but also a detailed knowledge about the genes playing a fundamental role in the progression of lactation. So far, very few GWAS have uncovered the genomic location and distribution of polymorphisms affecting milk yield and composition in goats. Martin et al. [1] genotyped, with the Goat SNP50 BeadChip, 2,209 Alpine and Saanen goats and performed association analyses with five dairy traits. Such work enabled the identification of 109 significant associations and further uncovered two polymorphisms in the DGAT1 gene that have major effects on fat content by modifying the activity of this enzyme [1]. In another recent study, Mucha et al. [2] detected a single nucleotide polymorphism (SNP) on goat chromosome 19 displaying a genome-wide significant association with milk yield as well as a number of chromosome-wide significant associations with dairy traits on chromosomes 4, 8, 14, and 29. Although these two studies represent a valuable step towards elucidating the genomic architecture of milk yield and composition traits in goats, analyzing a broader array of goat populations, as has been done in cattle [3], would provide a more comprehensive view of the genetic determinism of caprine dairy phenotypes.

The events promoting the initiation, maintenance and abrogation of lactation have been barely analyzed from a transcriptomic perspective in goats. Only one RNA-Seq study has investigated the changes experienced by the caprine mammary gland transcriptome across the production cycle (lactation vs. dry period) [4], while another one has compared the gene expression profile of goat milk somatic cells in colostrum and mature milk [5]. A third study investigated the transcriptomes of goat somatic cells, milk fat globules and blood cells via using microarrays [6]. This situation contrasts strongly with that of cattle, in which several studies outlining how the gene expression profile of the mammary gland changes in response to different experimental conditions have been published so far [7-10]. Indeed, RNA-Seq studies performed in dairy cattle [11] and also in sheep [12] have revealed that hundreds of genes are differentially expressed (DE) in the mammary gland when lactating vs. non-lactating individuals are compared. Multiple lines of evidence indicate that many of these genes are related to mammary gland development, protein and lipid metabolism processes, signal transduction, differentiation and immune function, being very significant the downregulation of the protein and lipid biosynthetic machinery $[11,12]$.

The work presented here had two main objectives: 1) Elucidating the changes in the mammary transcriptome associated with the lactation stage by sequencing total RNA from mammary gland biopsies retrieved from seven Murciano-Granadina goats sampled at $78 \mathrm{~d}$ (early lactation), $216 \mathrm{~d}$ (late lactation) and $285 \mathrm{~d}$ (dry period) post-partum, and 2) Identifying the genetic determinants of milk yield and composition traits in MurcianoGranadina goats through a GWAS approach comprising 822 individuals with records for 7 dairy traits registered during their $1^{\text {st }}$ lactation.

\section{Methods \\ Sequencing the mammary gland transcriptome along the lactation stage \\ Transcriptome sequencing}

Mammary biopsies were retrieved from 7 MurcianoGranadina goats at each of the three time points, i.e. $78.25 \pm 9.29 \mathrm{~d}$ (T1, early lactation), $216.25 \pm 9.29 \mathrm{~d}$ (T2, late lactation) and $285.25 \pm 9.29 \mathrm{~d}$ (T3, dry period) after parturition (Additional file 1: Table S1). The average age of the sampled goats was $5.88 \pm 1.89$ years and none of them was pregnant at T1, T2 or T3 (Additional file 1: Table S1). Mammary tissue was extracted with SPEEDYBELL 14G $150 \mathrm{~mm}$ semi-automatic biopsy needles (EVEREST Veterinary Technology, Barcelona, Spain) after applying local anesthesia to the region to be punctured. Samples were immediately submerged in RNAlater stabilization solution (Thermo Fisher Scientific, Barcelona, Spain) and shipped back to the laboratory for storage at $-80^{\circ} \mathrm{C}$.

For isolating total RNA, a small piece of mammary gland tissue was submerged into liquid nitrogen and grinded to a fine powder with a mortar and a pestle. Subsequently, this powder was homogenized in $1 \mathrm{~mL}$ TRIzol reagent (Thermo Fisher Scientific, Barcelona, Spain) with a homogenizer device (IKA T10 basic ULTRA-TURRAX, Barcelona, Spain). The Ambion RiboPure kit (Thermo Fisher Scientific, Barcelona, Spain) was used to purify total RNA in accordance with the instructions of the manufacturer. The concentration and purity of RNA preparations were evaluated with a Nanodrop ND-1000 spectrophotometer (Thermo Fisher Scientific, Barcelona, Spain), while RNA integrity was checked in a Bioanalyzer-2100 (Agilent Technologies, Santa Clara, CA) by using an Agilent RNA 6000 Nano kit (Agilent Technologies, Inc., Santa Clara, CA). The RNA integrity number (RIN) ranged between 6.00-8.40, with an average of $7.43 \pm 0.58$.

Paired-end sequencing $(2 \times 76 \mathrm{bp})$ of the RNA was performed in the Centre Nacional de Anàlisi Genòmica (CNAG-CRG, http://www.cnag.crg.eu/). The RNA-Seq library was prepared with KAPA Stranded mRNA-Seq Illumina Platforms Kit (Roche). Briefly, $500 \mathrm{ng}$ total RNA were used as the input material, the poly-A fraction was enriched with oligo-dT magnetic beads and the 
RNA was fragmented. The strand specificity was achieved during the second strand synthesis performed in the presence of dUTP. The blunt-ended double stranded cDNA was 3'-adenylated and Illumina platform compatible adaptors with unique dual indexes and unique molecular identifiers (Integrated DNA Technologies, Coralville, IA) were ligated. The ligation product was enriched by 15 cycles of PCR amplification and the quality of the final library was validated on an Agilent 2100 Bioanalyzer with the DNA 7500 assay (Agilent Technologies, Inc., Santa Clara, CA). The libraries were sequenced with a HiSeq 4000 instrument (Illumina, San Diego, CA) in a fraction of a HiSeq 4000 PE Cluster kit sequencing flow cell lane, following the manufacturer's protocol for dual indexing. Image analysis, base calling and quality scoring of the run were processed using the Real Time Analysis (RTA 2.7.7) tool and subsequently FASTQ sequence files were generated.

\section{Bioinformatic analyses of gene expression}

Sequencing quality was evaluated with the FastQC software v0.11.7 (https://www.bioinformatics.babraham.ac. $\mathrm{uk} /$ projects/fastqc/). Adaptors were automatically detected and removed by using the TrimGalore 0.5.0 tool (https:// www.bioinformatics.babraham.ac.uk/projects/trim_galore/), and we also trimmed reads shorter than $30 \mathrm{bp}$ or those with more than 5 ambiguous bases $(\mathrm{N})$. We excised $15 \mathrm{bp}$ from both ends of each read because sequencing errors are more frequent in these regions $[13,14]$. Clean reads were aligned to the goat reference genome ARS1 [15] with HISAT2 [16] by following the pipeline reported in [17]. The counts of unambiguously mapped reads of "proteincoding" features annotated in the general feature format (GFF) file were summarized by using the featureCounts tool [18]. Differential expression analyses were subsequently carried out by using DESeq2 software [19]. Correction for multiple testing was performed with the false discovery rate (FDR) procedure reported by Benjamini and Hochberg [20]. We considered that differential expression across two time points as relevant when two conditions were met: an absolute value of $\log _{2}$ fold change $\left(\log _{2} \mathrm{FC}\right)>1.5$ and a $q$-value $\leq 0.05$. Moreover, we analyzed the functional enrichment of $\mathrm{DE}$ genes by employing the DAVID Bioinformatics Resources 6.8 database $[21,22]$. This analysis was based on human and goat background gene sets, and statistical significance was set to a $q$-value $\leq 0.05$.

\section{Performance of a genome-wide association analysis for dairy traits \\ Phenotype recording}

The population sampled in the current work comprised 1,023 Murciano-Granadina goats raised in 15 farms affiliated to the National Association of Murciano-
Granadina Goat Breeders (CAPRIGRAN). All farms selected for this study were connected by artificial insemination. Raw records of phenotypic traits were routinely collected by CAPRIGRAN. Phenotypes under study included milk yield at $210 \mathrm{~d}$ (MY210), somatic cell count (SCC), fat percentage (FP), protein percentage (PP), lactose percentage (LP), dry matter percentage (DMP) and length of lactation (LOL). Phenotypes were normalized to a standard lactation of $210 \mathrm{~d}$ with the exception of LOL, which was not standardized. By filtering out individuals without complete phenotypic records, 822 goats remained for GWAS analyses.

\section{Genotyping with the goat SNP50 BeadChip}

Blood samples were collected in EDTA K3 coated vacuum tubes and stored at $-20^{\circ} \mathrm{C}$ before processing. Genomic DNA was isolated by using a modified saltingout procedure [23]. Briefly, $3 \mathrm{~mL}$ of whole blood were centrifuged at a speed of $2,000 \times g$ in the presence of 4 volumes of Red Cell Lysis Solution (Tris- $\mathrm{HCl} 10 \mathrm{mmol} /$ $\mathrm{L}, \mathrm{pH}=6.5$; EDTA $2 \mathrm{mmol} / \mathrm{L}$; Tween $201 \%$ ). The resulting white cell pellet was lysed with $3 \mathrm{~mL}$ lysis buffer (Tris- $\mathrm{HCl} 200 \mathrm{mmol} / \mathrm{L}, \mathrm{pH}=8$, EDTA $30 \mathrm{mmol} / \mathrm{L}$, SDS $1 \% ; \mathrm{NaCl} 250 \mathrm{mmol} / \mathrm{L}$ ) and proteins were degraded by using $100 \mu \mathrm{L}$ of proteinase $\mathrm{K}(20 \mathrm{mg} / \mathrm{mL})$. After a 3-h incubation step at $55^{\circ} \mathrm{C}$, the lysate was chilled and $1 \mathrm{~mL}$ of ammonium acetate $10 \mathrm{~mol} / \mathrm{L}$ was added to the lysate. After $10 \mathrm{~min}$ of centrifugation at $2,000 \times g$, the supernatant $(\sim 4 \mathrm{~mL})$ was transferred to a new tube containing $3 \mathrm{~mL}$ of isopropanol $96 \%$. Subsequently, samples were centrifuged at $2,000 \times g$ for $3 \mathrm{~min}$. Isopropanol was removed and the DNA pellet was washed with $3 \mathrm{~mL}$ of ethanol $70 \%$. After a centrifugation step at $2,000 \times g$ for 1 min, the DNA pellet was dried at room temperature and eluted with $1 \mathrm{~mL}$ of TE buffer (Tris- $\mathrm{HCl} 10 \mathrm{mmol} / \mathrm{L}$, EDTA $1 \mathrm{mmol} / \mathrm{L}, \mathrm{pH}=8$ ).

All goats were typed with the Goat SNP50 BeadChip (Illumina, USA) [24] according to the instructions of the manufacturer. Markers mapping to sex chromosomes, with calling rates $<90 \%$, or with minor allele frequencies $(\mathrm{MAF})<0.01$, or that deviated significantly from the Hardy-Weinberg expectation $\left(P \leq 1 \times 10^{-6}\right)$ were filtered out. Individuals with calling rates $<90 \%$ were also excluded. By integrating available phenotypic records, 48,722 single nucleotide polymorphisms (SNPs) and 822 goats passed the filtering criteria.

\section{Population structure and statistical analyses}

We investigated population structure through the principal component analysis (PCA) approach implemented in the smartPCA program of the EIGENSOFT package (version 6.1.4) [25]. The proportion of the variance explained by each significant $(P<0.05)$ principal component was computed with the twstats program [26]. 
Association analyses were performed with the Genomewide Efficient Mixed-Model Association (GEMMA, version 0.98) package [27] by fitting the following linear mixed model:

$$
\mathrm{Y}=\mathrm{W} \alpha+\mathrm{x} \beta+\mathrm{u}+\epsilon
$$

where $Y$ represents the vector of phenotypic values of the first lactation of 822 Murciano-Granadina goats; $W$ is a matrix with a column of $1 \mathrm{~s}$ and the fixed effects, i.e. farm (15 levels), year of birth (10 levels) and litter size (5 levels); $\alpha$ is a c-vector of the corresponding coefficients including the intercept; $x$ is a n-vector of marker genotypes in each individual; $\beta$ is the effect size of the marker (allele substitution effect); $u$ is a n-vector of random effects with a n-dimensional multivariate normal distribution $\left(0, \lambda \tau^{-1} K\right)$, being $\tau^{-1}$ the variance of the residual error, $\lambda$ the ratio between the two variance components and $K$ a $\mathrm{n} \times \mathrm{n}$ relatedness matrix derived from the 48,722 autosomal SNPs genotypes; and $\varepsilon$ is a vector of errors. In this study, the GEMMA package performs likelihood ratio tests for each SNP by contrasting the alternative hypothesis $\left(\mathrm{H}_{1}: \beta \neq 0\right)$ against the null hypothesis $\left(\mathrm{H}_{0}: \beta=0\right)$. Moreover, population structure is corrected by considering the relatedness matrix, which is built by taking into account all genome-wide SNPs as a random effect. After carrying out a correction for multiple testing based on a FDR approach [20], statistical significance was set to a $q$-value $\leq 0.05$.

We retrieved a list of protein-coding genes that mapped within the genomic boundaries $( \pm$ maximum distance of linkage disequilibrium decay, i.e. $988 \mathrm{~kb}$ ) of leading SNPs (i.e. the SNP showing the most significant association with a given trait) with the BEDTools v2.25.0 package [28]. The amount of linkage disequilibrium (LD) between adjacent SNPs was measured as the square of the correlation coefficient $\left(\mathrm{r}^{2}\right)$ by using the "--r2" instruction implemented in PLINK v1.9 [29]. The objective of this analysis was to check whether protein-coding genes within or near quantitative traits loci (QTLs) are differentially expressed across lactation.

\section{Results}

An analysis of the mammary gene expression patterns across goat lactation

\section{Differential expression analysis}

We have individually sequenced 21 RNA samples representing three lactation time points (T1, T2 and T3, see Methods). This experiment generated approximately 120 gigabases of raw data, i.e. an average of 65 million reads were obtained for each sample. The overall alignment rate obtained with HISAT2 $[16,17]$ was above $92 \%$. The uniquely mapped reads were summarized by using the featureCounts tool [18]. To reduce the influence of transcriptional noise, we removed the features with a number of raw counts below 10 in all samples. Principal component analysis (Fig. 1a) based on the expression profiles of each one of the 21 samples showed a clear separation between T3 (dry period) and T1/T2 (lactation) samples. Indeed, the first component explained $73 \%$ of the total variance. The only exception was sample T3-22, which clustered with T1/T2 samples (Fig. 1a, Additional file 2: Figure S1). Our interpretation is that this sample was retrieved from a goat that was not successfully dried off, so we decided to remove it from the data set. Although $\mathrm{T} 1$ and $\mathrm{T} 2$ samples represented two different time points of lactation (Fig. 1a, Additional file 2: Figure S1), they clustered tightly.

A total of 16,768 genes were found to be expressed in at least one of the 20 samples corresponding to the three lactation time points (T1, T2 and T3, see Methods). By establishing as a threshold of significance a $q$-value $\leq 0.05$ and an absolute $\log _{2} \mathrm{FC}>1.5$, we found 42 (T1 vs. T2), 1377 (T1 vs. T3) and 1,039 (T2 vs. T3) DE genes (Fig. 1b-d, Additional file 3: Tables S2-S4). The total set of 1,654 DE genes allowed us to differentiate T3 samples from the T1 and T2 samples (Fig. 2, Additional file 4: Figure S2). Moreover, there was a comparable number of upregulated and downregulated genes in the pairwise T1 vs. T2 (22 upregulated and 20 downregulated) and T1 vs. T3 (649 upregulated and 728 downregulated) comparisons, while in T2 vs. T3 the number of downregulated genes (695) exceeded that of upregulated genes (344) (Fig. 1b-d, Additional file 3: Tables S2-S4). In summary, our data evidenced that once lactation ceased, a large number of genes were downregulated (Fig. 1c-d, Additional file 3: Tables S3 and S4). As expected, genes encoding the main milk protein constituents such as casein $\alpha_{\mathrm{S} 1}$ (CSN1S1), casein $\alpha_{\mathrm{S} 2}$ (CSN1S2), casein $\beta$ (CSN2), casein $\mathrm{\kappa}(C S N 3)$, lactalbumin $\alpha(L A L B A)$ and progestagen-associated endometrial protein $(P A E P)$ were strongly downregulated at T3 (Table 1). The insulin receptor 1 (IRS1) gene, a master regulator of carbohydrate, lipid and protein metabolism, also decreased in expression at T3 (Table 1).

In T3, we also observed a marked downregulation of genes involved in lipid metabolic processes (Table 1), including: 1) Fatty acid synthesis, e.g. acetyl-CoA carboxylase $\alpha(A C A C A)$ and fatty acid synthase (FASN); 2) Triglyceride synthesis, e.g. glycerol-3-phosphate acyltransferase, mitochondrial (GPAM), 1-acylglycerol-3phosphate O-acyltransferase 1 (AGPAT1) and 4 (AGPAT4), glycerol-3-phosphate acyltransferase 2, mitochondrial (GPAT2) and 4 (GPAT4); 3) Cholesterol synthesis, e.g. 7-dehydrocholesterol reductase (DHCR7), 24-dehydrocholesterol reductase (DHCR24), lanosterol synthase (LSS), and methylsterol monooxygenase 1 


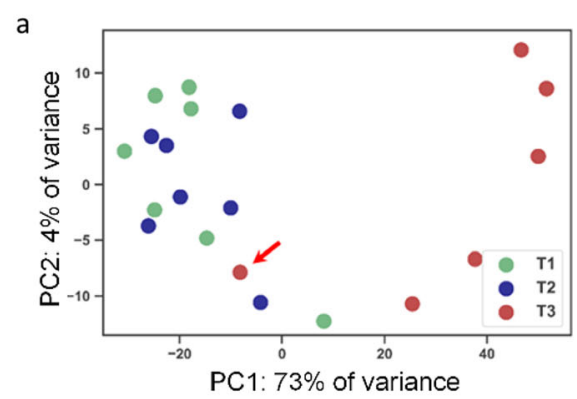

c

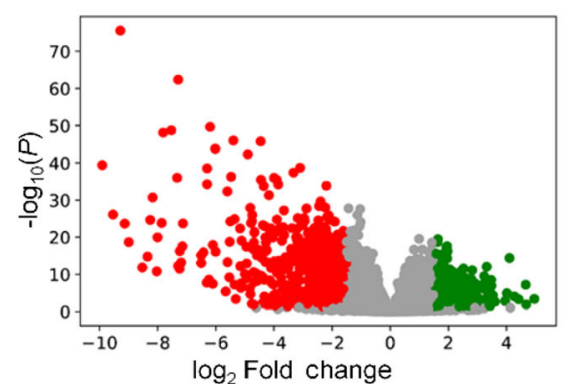

$b$

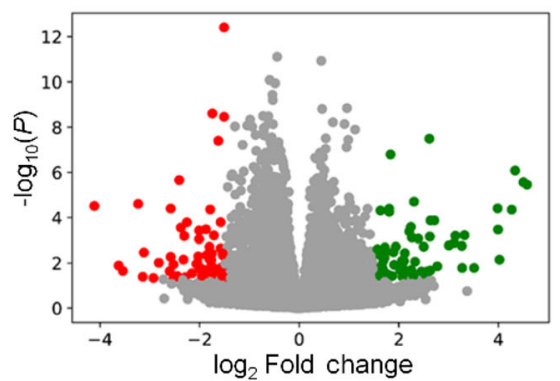

d

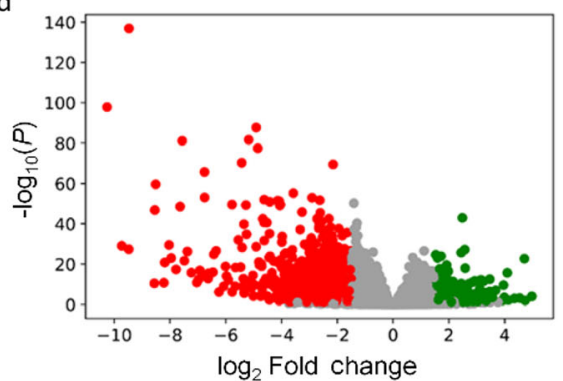

Fig. 1 a Principal component analysis (PCA) of mammary samples on the basis of read counts of "protein-coding" features annotated in the general feature format (GFF) file. These samples were obtained $78 \mathrm{~d}$ (T1, early lactation), $216 \mathrm{~d}$ (late lactation, T2) and $285 \mathrm{~d}$ (T3, dry period) after parturition. The red arrow indicates the sample T3-22, which clusters with T1 and T2 samples probably due to an unsuccessful dry-off (Additional file 2: Figure S1). b-d Volcano plots displaying differentially expressed genes in the pairwise comparisons T1 vs. T2 (b), T1 vs. T3 (c) and T2 vs. T3 (d). The red and green dots denote significantly downregulated and upregulated genes, respectively

(MSMO1); 4) Sphingolipid synthesis, e.g. sphingolipid biosynthesis regulator 3 (ORMDL3), oxysterol binding protein like 10 (OSBPL10) and 1A (OSBPL1A), serine palmitoyltransferase long chain base subunit 2 (SPTLC2) and 3 (SPTLC3); 5) Acetate synthesis and fatty acid activation, e.g. acetyl-coenzyme A synthetase 2 (ACSS2) and acyl-CoA synthetase long chain family member 1 (ACSL1); 6) Fatty acid desaturation, e.g. stearoyl-CoA desaturase $(S C D)$ and fatty acid desaturase 1 (FADS1); 7) Fatty acid absorption and transportation, e.g. CD36 molecule (CD36), low-density lipoprotein receptor $(L D L R)$, fatty acid binding protein 3 (FABP3) and apolipoprotein A5 (APOA5); 8) Formation of milk fat globules, e.g. butyrophilin subfamily 1 member A1 (BTN1A1), perilipin 2 (PLIN2), RAB18, member RAS oncogene family (RAB18), and milk fat globule-EGF factor 8 protein (MFGE8); 9) Lipolysis, e.g. lipoprotein lipase (LPL), lipase $\mathrm{G}$, endothelial type (LIPG), and pancreatic lipase related protein 2 (PNLIPRP2); 10) Transcriptional regulation of lipid metabolism, e.g. peroxisome proliferator activated receptor $\alpha$ (PPARA), estrogen receptor 2 (ESR2), leptin (LEP), and insulin-induced gene 1 (INSIG1).

The ceasing of lactation (T3) also involved an important decrease in the gene expression of solute carrier genes (Table 1) involved in the transportation of: 1) Carbohydrates, e.g. solute carrier family 2 member 1 (SLC2A1) and solute carrier family 35 member $\mathrm{C} 1$
(SLC35C1); 2) Amino acids, e.g. solute carrier family 1 member 1 (SLC1A1), solute carrier family 1 member 5 (SLC1A5), solute carrier family 7 member 14 (SLC7A14) and solute carrier family 36 member 2 (SLC36A2); and 3) Minerals, e.g. zinc (solute carrier family 30 member 4 , SLC30A4), copper (solute carrier family 31 member 1 , SLC31A1), divalent metals (solute carrier family 39 member 14, SLC39A14), to mention a few. With regard to the absorption of calcium, one of the main minerals present in milk, we observed a reduction in the expression of transient receptor potential cation channel subfamily $\mathrm{V}$ members 1 (TRPV1), while there was an upregulated expression of transient receptor potential cation channel subfamily $\mathrm{V}$ members 5 (TRPV5) and 6 (TRPV6). The gene expression of parathyroid hormonelike hormone (PTHLH) was reduced in the mammary gland at T3 but, at the same time, an increased expression of fibroblast growth factor 23 (FGF23) was also detected.

In general, genes involved in apoptosis displayed an upregulated expression in the mammary gland of goats at T3 (Table 1). Examples of these genes are the insulinlike growth factor binding protein 5 (IGFBP5), leukemia inhibitory factor $(L I F)$, suppressor of cytokine signaling 3 (SOCS3), BCL2 like 14 (BCL2L14), oncostatin M (OSM), oncostatin $\mathrm{M}$ receptor (OSMR), Fos proto-oncogene, AP-1 transcription factor subunit (FOS) and JunB protooncogene, AP-1 transcription factor subunit $(J U N B)$ as 


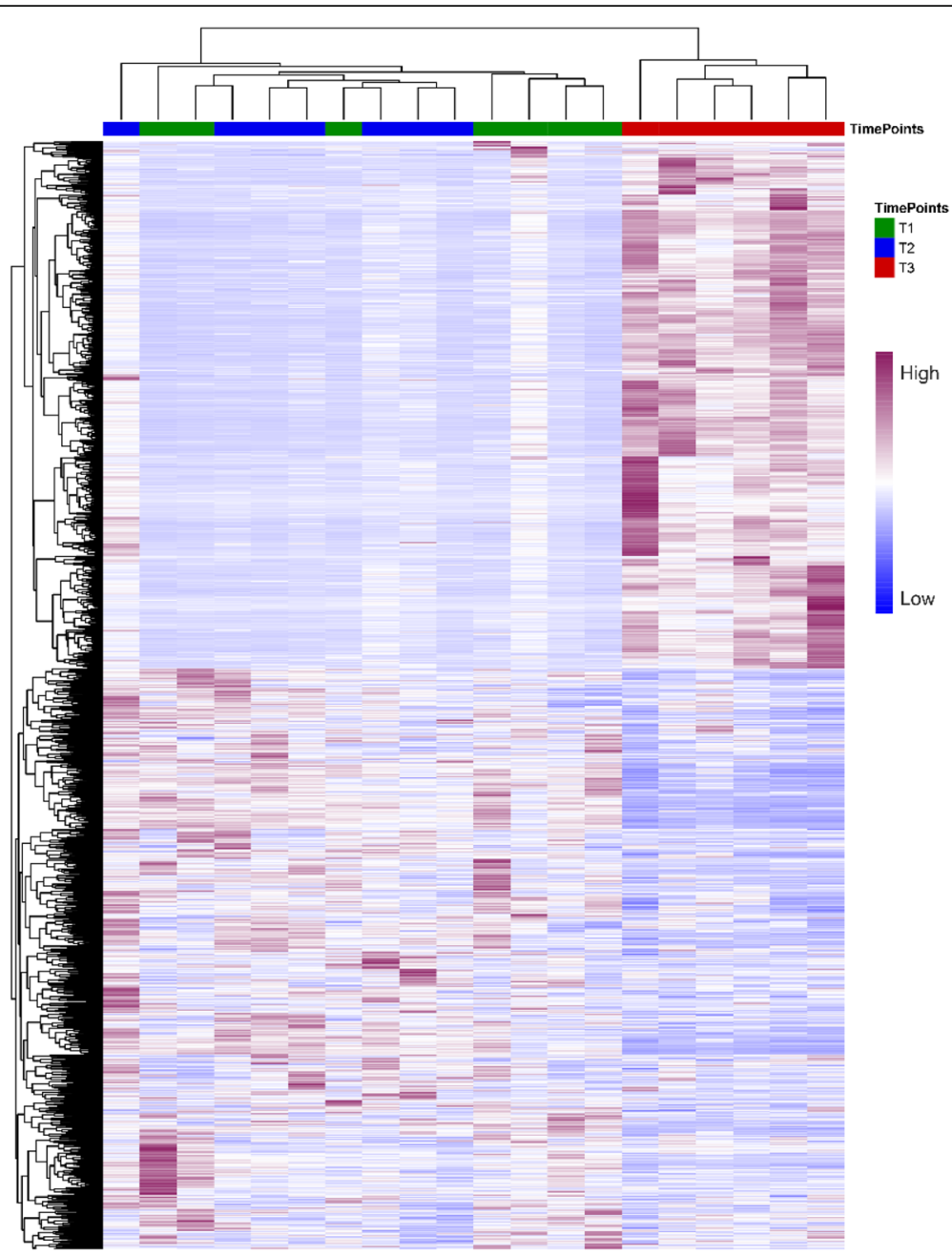

Fig. 2 Heatmap of read counts of 1654 differentially expressed genes identified in the three available comparisons (T1 vs. T2, T1 vs. T3 or T2 vs. T3). Samples were clustered by their read counts. The color scale varying from blue to purple depicts the number of read counts of differentially expressed genes which range from low to high, respectively

well as several genes belonging to the TNF superfamily such as tumor necrosis factor (TNF) and TNF receptor superfamily members 8 (TNFSF8), 13 (TNFSF13), 18 (TNFRSF18) and 6b (TNFRSF6B), and TNF- $\alpha$ induced protein 6 (TNFAIP6). In contrast, well known survival factors such as leukocyte receptor tyrosine kinase (LTK) and Wnt family member 5A (WNT5A) displayed a reduction in their expression at T3. Moreover, several genes belonging to the family of A disintegrin and metalloproteinase with thrombospondin motifs (ADAMTS), such as ADAMTS4, ADAMTS7, ADAMTS16 and ADAMTS17, which are involved in morphogenesis and tissue remodeling [30] increased in expression at T3.

With regard to genes involved in immunity, the dynamics of their expression profiles was quite heterogeneous (Table 1). Genes with key roles in mucosal immunity, e.g. mucin 1 (MUC1), 4 (MUC4) and 20 (MUC20), ATP binding cassette subfamily A member
$3(A B C A 3)$, and surfactant protein D (SFTPD), were downregulated at T3. In this time point, we also detected a decreased expression of several genes, e.g. the BPI fold containing family A member 1 (BPIFA1), member 2 (BPIFA2) and member 3 (BPIFA3), and the BPI fold containing family $\mathrm{B}$ member 1 (BPIFB1) and member 4 (BPIFB4), which have antimicrobial, surfactant and immunomodulatory properties, thus preventing the formation of bacterial biofilms [31]. In contrast, tight junction proteins claudin 6 (CLDN6) and D2 (CLDND2), which determine the permeability of the paracellular barrier [32], were highly upregulated at T3.

Finally, we detected an upregulation of a broad variety of immune response genes at T3 (Table 1), including: 1) Cytokines (and/or their receptors), e.g. interleukin 5 (IL5), interleukin 15 receptor subunit $\alpha$ (IL15RA) and interleukin 22 receptor subunit $\alpha_{2}$ (IL22RA2); 2) 
Table 1 List of differentially expressed genes mentioned in the main text

\begin{tabular}{|c|c|c|c|c|c|}
\hline \multirow[t]{2}{*}{ Main function } & \multirow{2}{*}{$\begin{array}{l}\text { Gene } \\
\text { symbol }\end{array}$} & \multicolumn{2}{|c|}{ T1 vs. T3 } & \multicolumn{2}{|c|}{ T2 vs. T3 } \\
\hline & & $\log _{2} \mathrm{FC}$ & $q$-value & $\log _{2} \mathrm{FC}$ & $q$-value \\
\hline \multirow[t]{6}{*}{ Milk protein composition } & CSNIS1 & -8.17 & $1.31 \mathrm{E}-28$ & -8.03 & $8.28 \mathrm{E}-28$ \\
\hline & CSNIS2 & -8.00 & $1.83 \mathrm{E}-18$ & -8.18 & 1.50E-19 \\
\hline & CSN2 & -7.24 & $5.06 \mathrm{E}-15$ & -7.23 & $9.68 \mathrm{E}-15$ \\
\hline & CSN3 & -5.16 & $2.76 \mathrm{E}-11$ & -5.12 & 4.67E-11 \\
\hline & LALBA & -9.53 & $3.72 \mathrm{E}-24$ & -9.47 & 8.10E-26 \\
\hline & PAEP & -4.67 & $8.16 \mathrm{E}-20$ & -4.41 & 1.61E-22 \\
\hline $\begin{array}{l}\text { Regulator of carbohydrate, lipid and protein } \\
\text { metabolism }\end{array}$ & IRSI & -1.85 & 1.60E-11 & - & - \\
\hline \multirow[t]{2}{*}{ Fatty acid synthesis } & $A C A C A$ & -3.10 & $3.26 \mathrm{E}-36$ & -2.69 & $1.31 \mathrm{E}-39$ \\
\hline & FASN & -4.46 & 4.34E-43 & -4.06 & $5.25 E-47$ \\
\hline \multirow[t]{5}{*}{ Triglyceride synthesis } & GPAM & -5.35 & $5.03 \mathrm{E}-23$ & -5.47 & $2.35 \mathrm{E}-17$ \\
\hline & AGPAT1 & -2.18 & $1.66 \mathrm{E}-23$ & -1.96 & $7.68 \mathrm{E}-27$ \\
\hline & AGPAT4 & -1.94 & $2.12 \mathrm{E}-02$ & -2.08 & $8.48 \mathrm{E}-03$ \\
\hline & GPAT2 & - & - & -2.80 & 3.49E-04 \\
\hline & GPAT4 & -2.70 & $8.24 \mathrm{E}-19$ & -2.44 & $6.98 \mathrm{E}-35$ \\
\hline \multirow[t]{4}{*}{ Cholesterol synthesis } & $D H C R 7$ & -2.53 & $1.57 \mathrm{E}-20$ & -2.91 & 1.40E-50 \\
\hline & DHCR24 & -4.00 & $1.15 \mathrm{E}-33$ & -4.14 & 3.81E-49 \\
\hline & LSS & -1.82 & $3.88 \mathrm{E}-19$ & -2.30 & $1.60 \mathrm{E}-40$ \\
\hline & MSMO1 & -2.47 & $1.01 \mathrm{E}-22$ & -2.93 & 3.50E-31 \\
\hline \multirow[t]{5}{*}{ Sphingolipid synthesis } & ORMDL3 & -2.24 & $3.76 \mathrm{E}-19$ & -2.16 & 3.44E-30 \\
\hline & OSBPL10 & -1.63 & $6.25 \mathrm{E}-06$ & - & - \\
\hline & OSBPLIA & -1.62 & 4.00E-13 & - & - \\
\hline & SPTLC2 & -1.73 & $1.56 \mathrm{E}-18$ & - & - \\
\hline & SPTLC3 & -1.54 & 2.92E-06 & - & - \\
\hline \multirow[t]{2}{*}{ Acetate synthesis and fatty acid activation } & ACSS2 & -2.26 & $5.04 \mathrm{E}-26$ & -2.53 & 1.57E-31 \\
\hline & ACSL1 & -1.98 & $7.21 \mathrm{E}-09$ & -1.97 & 7.05E-13 \\
\hline \multirow[t]{2}{*}{ Fatty acid desaturation } & $S C D$ & -6.30 & $4.75 E-32$ & -6.43 & $2.17 E-23$ \\
\hline & FADS1 & -2.23 & $5.87 E-26$ & -2.41 & 4.70E-25 \\
\hline \multirow[t]{4}{*}{ Fatty acid absorption and transportation } & CD36 & -2.64 & $5.12 \mathrm{E}-16$ & -2.59 & $6.81 \mathrm{E}-20$ \\
\hline & $L D L R$ & -1.72 & 7.96E-08 & -2.37 & 3.19E-20 \\
\hline & FABP3 & -5.00 & 1.93E-09 & -5.37 & 5.60E-12 \\
\hline & APOA5 & -5.12 & 3.17E-07 & -5.08 & 8.00E-08 \\
\hline \multirow[t]{4}{*}{ Milk fat globules } & BTN1A1 & -6.43 & $1.02 \mathrm{E}-14$ & -6.46 & $5.80 \mathrm{E}-15$ \\
\hline & PLIN2 & -2.00 & $6.30 \mathrm{E}-11$ & -1.96 & 7.69E-15 \\
\hline & $R A B 18$ & -2.65 & $1.05 \mathrm{E}-16$ & -2.32 & 4.00E-15 \\
\hline & MFGE8 & -3.84 & 1.67E-20 & -4.09 & $5.24 \mathrm{E}-49$ \\
\hline \multirow[t]{3}{*}{ Lipolysis } & $L P L$ & -5.60 & $3.33 \mathrm{E}-30$ & -5.78 & 2.29E-47 \\
\hline & LIPG & -4.10 & $7.56 \mathrm{E}-11$ & -4.25 & 1.14E-11 \\
\hline & PNLIPRP2 & - & - & -2.46 & $1.12 \mathrm{E}-02$ \\
\hline \multirow[t]{4}{*}{ Transcriptional regulation of lipid metabolism } & PPARA & -1.63 & $1.78 \mathrm{E}-18$ & - & - \\
\hline & ESR2 & -1.62 & 8.77E-08 & - & - \\
\hline & LEP & -4.01 & $2.11 \mathrm{E}-04$ & -5.39 & 2.39E-08 \\
\hline & $|N S| G \mid$ & -4.35 & $1.29 \mathrm{E}-31$ & -5.18 & $9.72 \mathrm{E}-79$ \\
\hline
\end{tabular}


Table 1 List of differentially expressed genes mentioned in the main text (Continued)

\begin{tabular}{|c|c|c|c|c|c|}
\hline \multirow[t]{2}{*}{ Main function } & \multirow{2}{*}{$\begin{array}{l}\text { Gene } \\
\text { symbol }\end{array}$} & \multicolumn{2}{|c|}{ T1 vs. T3 } & \multicolumn{2}{|c|}{ T2 vs. T3 } \\
\hline & & $\log _{2} \mathrm{FC}$ & $q$-value & $\log _{2} \mathrm{FC}$ & $q$-value \\
\hline \multirow[t]{2}{*}{ Transportation of carbohydrates } & $S L C 2 A 1$ & -2.18 & $2.76 \mathrm{E}-19$ & -2.00 & $2.34 \mathrm{E}-17$ \\
\hline & SLC35C1 & -2.94 & $1.59 \mathrm{E}-22$ & -2.85 & $8.11 \mathrm{E}-23$ \\
\hline \multirow[t]{4}{*}{ Transportation of amino acids } & SLCIA1 & -2.14 & 4.08E-07 & -2.01 & $3.14 \mathrm{E}-06$ \\
\hline & SLCIAS & -2.29 & $3.79 \mathrm{E}-09$ & -2.28 & $5.58 \mathrm{E}-14$ \\
\hline & SLC7A14 & -1.83 & 4.38E-03 & -1.84 & 4.00E-03 \\
\hline & SLC36A2 & -1.53 & $2.19 \mathrm{E}-03$ & - & - \\
\hline \multirow[t]{3}{*}{ Transportation of minerals } & SLC30A4 & -2.70 & $1.37 \mathrm{E}-11$ & -1.95 & 4.49E-12 \\
\hline & SLC31A1 & -1.69 & $1.96 \mathrm{E}-10$ & -1.53 & $6.50 \mathrm{E}-09$ \\
\hline & SLC39A14 & -1.72 & $1.31 \mathrm{E}-09$ & -1.68 & 7.69E-11 \\
\hline \multirow[t]{5}{*}{ Absorption of calcium } & TRPV1 & -3.43 & 4.50E-06 & -2.83 & 2.64E-07 \\
\hline & TRPV5 & 4.66 & 7.54E-07 & 3.68 & $1.15 \mathrm{E}-06$ \\
\hline & TRPV6 & 3.25 & 7.87E-06 & 3.25 & $8.06 \mathrm{E}-11$ \\
\hline & PTHLH & -5.17 & $1.04 \mathrm{E}-20$ & -5.41 & $1.28 \mathrm{E}-26$ \\
\hline & FGF23 & 3.48 & $1.21 \mathrm{E}-06$ & 2.33 & $5.21 \mathrm{E}-03$ \\
\hline \multirow[t]{16}{*}{ Apoptosis } & IGFBP5 & - & - & -1.76 & 2.01E-05 \\
\hline & LIF & 2.58 & $3.05 \mathrm{E}-05$ & 1.86 & 4.80E-04 \\
\hline & sOCS3 & 2.65 & $2.64 \mathrm{E}-05$ & 2.49 & $1.66 \mathrm{E}-06$ \\
\hline & BCL2L14 & 1.53 & $1.55 \mathrm{E}-06$ & 1.68 & 4.06E-12 \\
\hline & OSM & 1.90 & 1.46E-04 & - & - \\
\hline & OSMR & 1.64 & $6.38 \mathrm{E}-04$ & 1.56 & $6.14 \mathrm{E}-09$ \\
\hline & FOS & 1.67 & 5.82E-03 & 1.72 & 2.61E-04 \\
\hline & JUNB & 2.06 & 4.59E-06 & 1.80 & 4.63E-11 \\
\hline & TNF & 1.78 & 8.90E-06 & - & - \\
\hline & TNFSF8 & 1.66 & 8.87E-12 & - & - \\
\hline & TNFSF13 & - & - & -2.48 & $3.33 \mathrm{E}-17$ \\
\hline & TNFRSF18 & 2.10 & $6.21 \mathrm{E}-05$ & 1.59 & 1.04E-04 \\
\hline & TNFRSF6B & 1.64 & $6.44 \mathrm{E}-04$ & - & - \\
\hline & TNFAIPG & 1.81 & 1.41E-05 & - & - \\
\hline & LTK & -2.45 & $2.59 \mathrm{E}-26$ & -2.31 & 2.79E-19 \\
\hline & WNT5A & -2.50 & $5.73 \mathrm{E}-20$ & -2.28 & 5.87E-26 \\
\hline \multirow[t]{4}{*}{ Morphogenesis and tissue remodeling } & ADAMTS4 & 2.46 & $5.84 \mathrm{E}-05$ & 1.61 & 2.64E-03 \\
\hline & ADAMTS7 & 1.59 & 2.43E-06 & - & - \\
\hline & ADAMTS16 & 1.69 & $2.46 \mathrm{E}-03$ & - & - \\
\hline & ADAMTS17 & -1.54 & 1.18E-09 & -1.64 & $2.02 \mathrm{E}-09$ \\
\hline \multirow[t]{9}{*}{ Immunity } & MUC1 & -3.11 & $2.59 \mathrm{E}-05$ & -2.78 & 1.21E-04 \\
\hline & MUC4 & -2.10 & $7.80 \mathrm{E}-05$ & -1.81 & 1.03E-05 \\
\hline & MUC20 & -3.01 & 4.49E-15 & -2.78 & $1.09 \mathrm{E}-13$ \\
\hline & $A B C A 3$ & -2.61 & 7.95E-21 & -1.94 & $3.98 \mathrm{E}-20$ \\
\hline & SFTPD & -5.47 & $6.59 \mathrm{E}-34$ & -5.35 & $6.57 \mathrm{E}-38$ \\
\hline & BPIFA1 & -4.41 & $2.67 \mathrm{E}-13$ & -3.86 & $5.54 \mathrm{E}-08$ \\
\hline & BPIFA2 & -8.53 & $5.70 \mathrm{E}-11$ & -6.61 & 1.56E-14 \\
\hline & BPIFA3 & -5.11 & $1.34 \mathrm{E}-17$ & -4.08 & $6.36 \mathrm{E}-09$ \\
\hline & BPIFBI & -4.32 & $3.14 \mathrm{E}-21$ & -4.28 & 3.16E-20 \\
\hline
\end{tabular}


Table 1 List of differentially expressed genes mentioned in the main text (Continued)

\begin{tabular}{|c|c|c|c|c|c|}
\hline \multirow[t]{2}{*}{ Main function } & \multirow{2}{*}{$\begin{array}{l}\text { Gene } \\
\text { symbol }\end{array}$} & \multicolumn{2}{|c|}{ T1 vs. T3 } & \multicolumn{2}{|c|}{ T2 vs. T3 } \\
\hline & & $\log _{2} \mathrm{FC}$ & $q$-value & $\log _{2} \mathrm{FC}$ & $q$-value \\
\hline & BPIFB4 & -3.93 & $8.81 \mathrm{E}-03$ & - & - \\
\hline & CLDN6 & 3.09 & $1.68 \mathrm{E}-03$ & - & - \\
\hline & CLDND2 & 1.68 & 1.57E-08 & 1.72 & $1.61 \mathrm{E}-22$ \\
\hline \multirow[t]{3}{*}{ Cytokines and/or their receptors } & 115 & 1.76 & 8.96E-03 & - & - \\
\hline & IL15RA & 1.90 & 3.49E-07 & - & - \\
\hline & IL22RA2 & 1.99 & $9.41 \mathrm{E}-03$ & - & - \\
\hline \multirow[t]{2}{*}{ Defensins } & DEFB116 & 2.75 & 2.34E-02 & 2.73 & $9.28 \mathrm{E}-03$ \\
\hline & DEFB126 & 3.40 & 2.70E-03 & 3.55 & $2.21 \mathrm{E}-04$ \\
\hline Chemokines & CXCR4 & 1.67 & 1.67E-05 & - & - \\
\hline \multirow[t]{6}{*}{ Complement cascade } & CIQA & 1.60 & 1.77E-07 & - & - \\
\hline & C1S & 1.69 & 8.27E-06 & - & - \\
\hline & $C 1 R$ & 1.76 & 4.57E-05 & - & - \\
\hline & C6 & 2.25 & $1.53 \mathrm{E}-07$ & 1.83 & $2.36 \mathrm{E}-06$ \\
\hline & $C 7$ & 1.95 & $1.04 \mathrm{E}-03$ & - & - \\
\hline & CTSL & 1.78 & 8.36E-03 & - & - \\
\hline
\end{tabular}

The dash symbol indicates the absence of a significant differential expression; $\log _{2}$ FC: $\log _{2}$ of the fold-change in expression. A negative log ${ }_{2}$ FC value indicates that mRNA expression is downregulated in T3

Defensins, e.g. defensin $\beta 116$ (DEFB116) and $\beta 126$ (DEFB126); 3) Chemokines, e.g. C-X-C motif chemokine receptor 4 (CXCR4); and 4) Genes participating in the complement cascade, e.g. complement $\mathrm{C} 1 \mathrm{q}$ A chain $(C 1 Q A)$, complement $\mathrm{C} 1 \mathrm{~s}(C 1 S)$, complement $\mathrm{C} 1 \mathrm{r}$ $(C 1 R)$, complement $6(C 6)$, complement $7(C 7)$ and cathepsin L (CTSL).

\section{Functional enrichment of differentially expressed genes}

Due to the incomplete annotation of goat genes, the functional enrichment analysis of the 1,654 DE genes was based on both human and goat background gene sets retrieved from the DAVID database [21, 22]. As a result, we identified 10 pathways that were significantly enriched based on the human background gene set ( $q$ value $\leq 0.05$, Additional file 5: Table S5), and 11 significant pathways based on the goat background gene set ( $q$-value $\leq 0.05$, Additional file 5: Table S6). Six pathways were consistently detected in both analyses, i.e. PPAR signaling, metabolic pathways, steroid biosynthesis, complement and coagulation cascades, biosynthesis of antibiotics and adipocytokine signaling (Table 2). Moreover, the gene ontology (GO) analysis based on human background genes allowed us to detect 45 significant terms, while no term was identified when the goat background genes were used (Additional file 5: Tables S5 and S6).

\section{Identification of genomic regions associated with dairy traits}

Descriptive statistics of seven dairy traits recorded in Murciano-Granadina goats are shown in Additional file 6:
Table S7. The average values of milk fat percentage, protein percentage and milk yield normalized to $210 \mathrm{~d}$ were $5.20 \% \pm 0.85 \%, 3.56 \% \pm 0.41 \%$ and $387.65 \pm 134.79 \mathrm{~kg}$, respectively. Moreover, all traits showed a normal distribution with the exception of the somatic cell count (SCC), which was logarithmically transformed to achieve normality (Additional file 7: Figure S3). The analysis of the Murciano-Granadina individuals by PCA clustering based on the genotypes of the 48,722 available markers did not show any sign of population stratification (Additional file 8: Figure S4).

By performing association analyses between SNP genotypes and dairy traits recorded in 822 MurcianoGranadina goats, we identified 24 quantitative trait loci (QTLs) that reached the threshold of significance ( $q$-value $\leq 0.05$, Table 3 ) either at the genome-wide or chromosome-wide levels. Quantitative trait locus 6 (QTL6) on chromosome 6 was highly associated with protein percentage at the genome-wide level of significance $\left(78.90-93.48 \mathrm{Mb}, q\right.$-value $=1.54 \times 10^{-06}$, Fig. 3, Table 3), and also with dry matter $(84.67-86.86 \mathrm{Mb}$, $q$-value $\left.=2.66 \times 10^{-02}\right)$ and fat percentages $(86.86 \mathrm{Mb}$, $q$-value $=1.36 \times 10^{-02}$ ) at the chromosome-wide level of significance. In addition, we found genome-wide significant associations for lactose percentage on chromosome 2 (QTL1, 130.72-131.01 Mb, q-value = $7.26 \times 10^{-03}$, Fig. 4a), as well as for protein and dry matter percentages on chromosome 17 (QTL17, 11.20 Mb, Figs. 3a and 4b). At the chromosome-wide level, we found 21 significant associations (Table 3) but only two of them were supported by more than 2 
Table 2 Enriched pathways in the set of 1,654 differentially expressed genes (T1-T2, T1-T3 and T2-T3)

\begin{tabular}{|c|c|c|c|c|c|c|c|c|}
\hline \multirow[t]{2}{*}{ Name } & \multicolumn{4}{|c|}{ Human background gene set } & \multicolumn{4}{|c|}{ Goat background gene set } \\
\hline & Number & $P$ value & Fold enrichment & q-value & Number & $P$ value & Fold enrichment & $q$-value \\
\hline PPAR signaling pathway & 18 & 2.01E-06 & 3.86 & 2.65E-05 & 22 & 8.86E-08 & 3.84 & $1.16 \mathrm{E}-06$ \\
\hline Steroid biosynthesis & 9 & 3.06E-05 & 6.46 & 4.03E-04 & 10 & $2.58 \mathrm{E}-05$ & 5.63 & $3.38 \mathrm{E}-04$ \\
\hline Complement and coagulation cascades & 16 & 5.85E-05 & 3.33 & 7.70E-04 & 18 & $2.78 \mathrm{E}-05$ & 3.19 & $3.65 \mathrm{E}-04$ \\
\hline Metabolic pathways & 116 & $1.75 \mathrm{E}-04$ & 1.37 & 2.30E-03 & 141 & $6.68 \mathrm{E}-06$ & 1.41 & $8.78 \mathrm{E}-05$ \\
\hline Biosynthesis of antibiotics & 28 & 1.49E-03 & 1.90 & 1.95E-02 & 30 & $2.58 \mathrm{E}-03$ & 1.78 & $3.34 \mathrm{E}-02$ \\
\hline Adipocytokine signaling pathway & 13 & 2.89E-03 & 2.67 & 3.73E-02 & 14 & $3.46 \mathrm{E}-03$ & 2.48 & $4.45 \mathrm{E}-02$ \\
\hline
\end{tabular}

These are the pathways that were consistently detected in the analyses based on human and goat background gene sets

Table 3 Quantitative trait loci (QTL) associated with milk traits recorded in Murciano-Granadina goats

\begin{tabular}{|c|c|c|c|c|c|c|c|c|c|}
\hline QTL & Chromosome & Leading SNP & Position, Mb & \#SNPS & MAF & Trait & $\beta \pm S E$ & $P$ value & $q$-value \\
\hline 1 & 2 & rs268253425 & $130.72-130.01$ & 2 & 0.20 & LP & $-0.09 \pm 0.02$ & $1.50 \mathrm{E}-07$ & $7.26 \mathrm{E}-03$ \\
\hline 2 & 3 & rs268258472 & 113.47 & 1 & 0.38 & LOL & $-14.20 \pm 3.21$ & $1.04 \mathrm{E}-05$ & $2.38 \mathrm{E}-02$ \\
\hline 3 & 6 & rs268259784 & 4.40 & 1 & 0.35 & PP & $0.07 \pm 0.02$ & $8.21 \mathrm{E}-04$ & 4.09E-02 \\
\hline 4 & 6 & rs268251267 & 15.64 & 1 & 0.24 & PP & $0.08 \pm 0.03$ & $7.85 \mathrm{E}-04$ & 4.00E-02 \\
\hline \multirow[t]{2}{*}{5} & 6 & rs268259390 & 56.51 & 1 & 0.02 & DMP & $1.08 \pm 0.26$ & 4.56E-05 & $3.56 \mathrm{E}-02$ \\
\hline & & & & & & PP & $0.29 \pm 0.07$ & $6.52 \mathrm{E}-05$ & $8.48 \mathrm{E}-03$ \\
\hline \multirow[t]{3}{*}{6} & 6 & rs268290907 & 78.90-93.48 & 12 & 0.43 & PP & $-0.14 \pm 0.02$ & $3.19 \mathrm{E}-11$ & $1.54 \mathrm{E}-06$ \\
\hline & 6 & rs268268356 & $84.67-86.86$ & 2 & 0.40 & DMP & $-0.35 \pm 0.08$ & 1.14E-05 & $2.66 \mathrm{E}-02$ \\
\hline & 6 & rs268290907 & 86.86 & 1 & 0.43 & $\mathrm{FP}$ & $-0.18 \pm 0.04$ & 5.79E-06 & $1.36 \mathrm{E}-02$ \\
\hline 7 & 11 & rs268250457 & 72.83 & 1 & 0.41 & LOL & $15.23 \pm 3.30$ & 4.40E-06 & $9.13 \mathrm{E}-03$ \\
\hline 8 & 12 & rs 268256521 & 68.10 & 1 & 0.12 & LOL & $-20.35 \pm 4.76$ & 2.07E-05 & $3.50 \mathrm{E}-02$ \\
\hline 9 & 13 & rs268236131 & $53.62-54.38$ & 2 & 0.32 & SCC & $0.22 \pm 0.05$ & $1.92 \mathrm{E}-05$ & $3.05 \mathrm{E}-02$ \\
\hline 11 & 14 & rs268255959 & 46.10 & 1 & 0.09 & LP & $-0.10 \pm 0.02$ & $2.56 \mathrm{E}-05$ & 4.77E-02 \\
\hline 10 & 14 & rs268282962 & 56.92 & 1 & 0.01 & FP & $0.78 \pm 0.18$ & $1.78 \mathrm{E}-05$ & $3.32 \mathrm{E}-02$ \\
\hline 12 & 15 & rs268235117 & 34.69 & 1 & 0.06 & MY210 & $-61.98 \pm 13.53$ & 4.95E-06 & 7.91E-03 \\
\hline 13 & 15 & rs268290053 & 35.51 & 1 & 0.07 & FP & $0.35 \pm 0.08$ & 4.82E-06 & 7.69E-03 \\
\hline 14 & 15 & rs268266747 & 63.95 & 1 & 0.23 & SCC & $0.23 \pm 0.05$ & $1.63 \mathrm{E}-05$ & $2.60 \mathrm{E}-02$ \\
\hline 15 & 16 & rs268236985 & 39.59 & 1 & 0.04 & DMP & $0.81 \pm 0.20$ & 6.39E-05 & 4.93E-02 \\
\hline 16 & 16 & rs268253363 & 47.67 & 1 & 0.21 & DMP & $0.42 \pm 0.10$ & 1.70E-05 & $2.62 \mathrm{E}-02$ \\
\hline \multirow[t]{2}{*}{17} & 17 & rs268238952 & 11.20 & 1 & 0.06 & PP & $0.22 \pm 0.05$ & 4.84E-06 & 2.13E-02 \\
\hline & & & & & & DMP & $0.88 \pm 0.17$ & $3.89 \mathrm{E}-07$ & $1.88 \mathrm{E}-02$ \\
\hline 18 & 18 & rs268278435 & 29.64 & 1 & 0.04 & DMP & $0.84 \pm 0.19$ & 1.33E-05 & $1.70 \mathrm{E}-02$ \\
\hline 19 & 20 & rs268277231 & 29.45 & 1 & 0.08 & $L P$ & $-0.11 \pm 0.03$ & $3.35 \mathrm{E}-05$ & $4.84 \mathrm{E}-02$ \\
\hline 20 & 22 & rs268253724 & 25.30 & 1 & 0.36 & FP & $-0.18 \pm 0.04$ & 4.14E-05 & $4.68 \mathrm{E}-02$ \\
\hline 21 & 23 & rs 268243170 & 8.15 & 1 & 0.45 & MY210 & $29.89 \pm 6.76$ & 1.03E-05 & $1.01 \mathrm{E}-02$ \\
\hline 22 & 24 & rs 268240589 & 49.71 & 1 & 0.32 & $L P$ & $0.07 \pm 0.02$ & $9.51 \mathrm{E}-06$ & $1.23 \mathrm{E}-02$ \\
\hline 23 & 28 & rs 268240830 & 23.02 & 1 & 0.42 & $L P$ & $-0.06 \pm 0.01$ & 7.16E-05 & $1.66 \mathrm{E}-02$ \\
\hline 24 & 28 & rs268246445 & $41.15-41.42$ & 4 & 0.51 & LP & $-0.06 \pm 0.01$ & $3.21 \mathrm{E}-05$ & $1.51 \mathrm{E}-02$ \\
\hline
\end{tabular}

QTL Quantitative trait locus; Genome-wide significant associations are indicated in bold; leading SNP: a SNP showing the most significant association with a given trait, \#SNPs number of SNPS, MAF minor allele frequency, $P P$ protein percentage, $F P$ fat percentage, $L P$ lactose percentage, DMP dry matter percentage, SCC somatic cell count, $L O L$ length of lactation, MY210 milk yield normalized to $210 \mathrm{~d} ; \beta$ and SE denote the effect size of the marker (allele substitution effect) and its standard error, respectively 
SNPs (QTL9 for somatic cell count and QTL24 for lactose percentage, Table 3).

According to data presented in Additional file 9: Figure $\mathrm{S} 5$, the maximum distance at which $\mathrm{r}^{2}$ decays to its minimum value is $988 \mathrm{~kb}$. Based on this, we retrieved 490 protein-coding genes mapping to $\pm 988 \mathrm{~kb}$ of the leading SNP corresponding to each QTL. This list of genes was compared with the list of genes DE across lactation time points. By doing so, we found 39 genes mapping to 14 QTLs that are also DE (Table 4). For instance, the QTL6 region, which shows significant associations with protein, fat and dry matter percentages, contains the casein genes, which are downregulated in T3 (Tables 3 and 4).

\section{Discussion}

The expression profiles of the goat mammary gland in early and late lactation are similar

The number of DE genes in $\mathrm{T} 1$ vs. T2 was quite low (only 42 genes were $\mathrm{DE}$ ), implying that the physiological and metabolic state of the mammary gland in these two time points is not remarkably different. In sheep milk, an analysis of differential expression revealed 22 (d 10 vs. 50), 20 (d 50 vs. 120), 277 (d 10 vs. 120), 135 (d 50 vs. 150) and 578 (d 10 vs. 150) DE genes [12]. The comparison that more closely resembles ours (d 50 vs. 150, $135 \mathrm{DE}$ genes) highlighted a higher number of DE genes than us. Many biological and technical factors might have produced this discrepancy. For instance, we have used mammary tissue while Suárez-Vega et al. [12] employed milk somatic cells as a source of RNA. Moreover, the shape and duration of the lactation curve is different in sheep and goats. Despite these differences, a steady increase was observed in the expression of the carboxypeptidase X, M14 family member 2 (CPXM2) gene by Suárez-Vega et al. [12] and us. This gene might have an important role in mammary gland development and involution [12]. Moreover, Suárez-Vega et al. [12] and us observed an upregulation of the gene encoding $\gamma$-aminobutyric acid receptor subunit $\beta_{3}$ (GABRB3) at $\mathrm{T} 2$, a change that has also been observed in rat lactation [33]. We have also detected an upregulation of the arylsulfatase family member I (ARSI), inhibin subunit $\beta$ A (INHBA) and tenascin $\mathrm{R}(T N R)$ genes in $\mathrm{T} 2$, which might be indicative of the tissue remodeling and progressive involution that the mammary gland experiences through the progression of lactation [34-36]. In T2, the upregulated ST $8 \alpha$-N-Acetyl-Neuraminide $\alpha-2$, 8-Sialyltransferase 6 (ST8SIA6) and polypeptide Nacetylgalactosaminyltransferase $14 \quad$ (GALNT14) genes

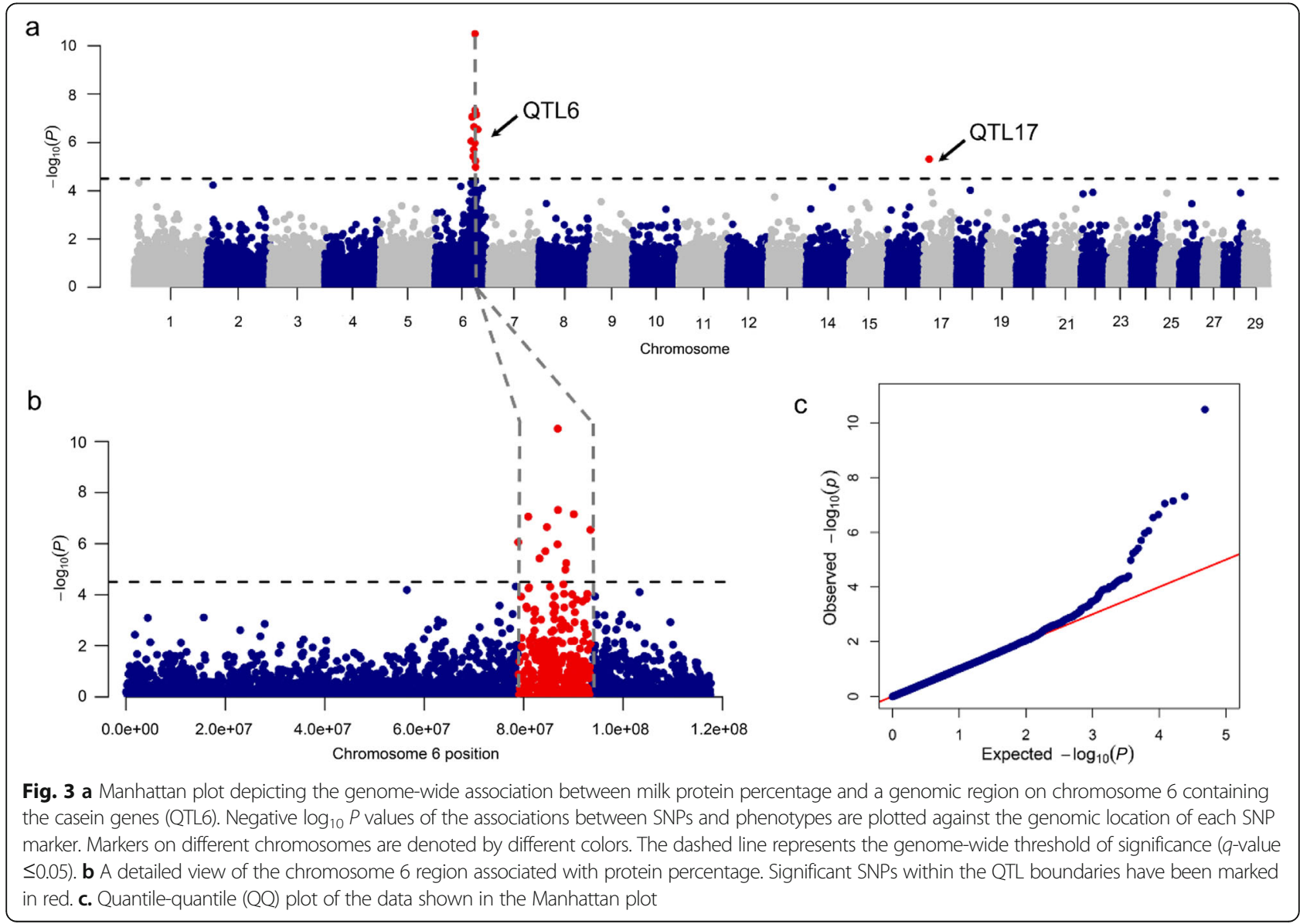



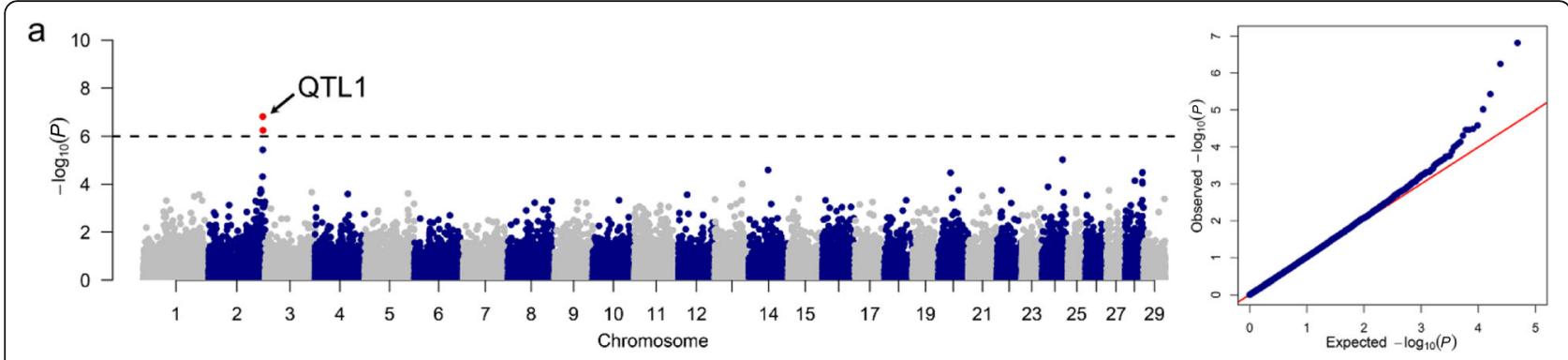

b
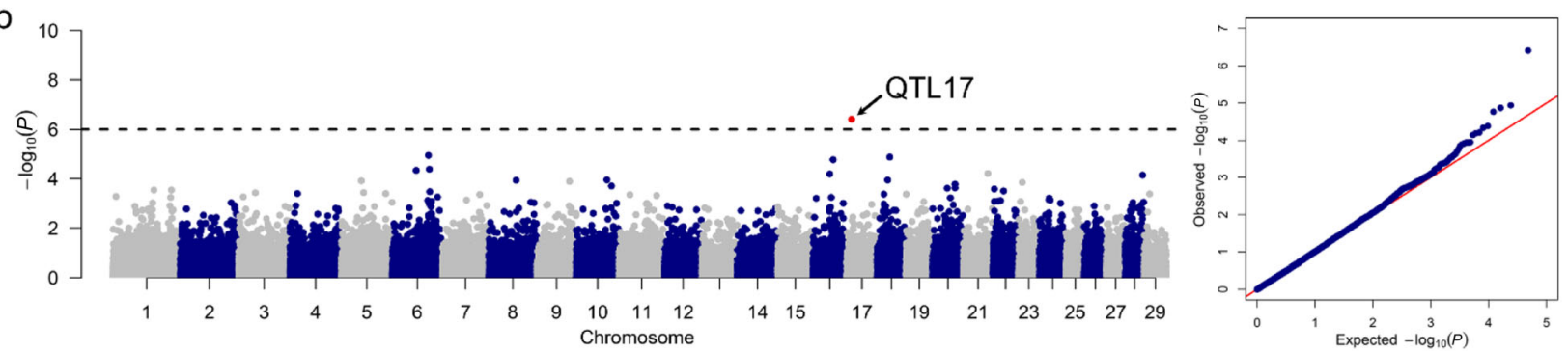

Fig. 4 a Manhattan plot depicting the genome-wide significant associations between SNP markers and lactose percentage. The corresponding quantile-quantile (QQ) plot is shown at the right side of the Manhattan plot. b Manhattan plot depicting the genome-wide significant associations between SNP markers and dry matter percentage. The corresponding quantile-quantile (QQ) plot is shown at the right side of the Manhattan plot. Negative $\log _{10} P$ values of the associations between SNPs and phenotypes are plotted against the genomic location of each marker SNP. Markers on different chromosomes are denoted by different colors. The dashed lines represent the genome-wide threshold of significance $(q$-value $\leq 0.05)$

respectively catalyze the formation of milk sialoglycoconjugates [37] and the O-glycosylation of mucins [38]. Finally, two molecules, i.e. adiponectin $(A D I P O Q)$ and hexokinase domain containing 1 (HKDC1), showed an increased and reduced expression in $\mathrm{T} 2$, respectively. These two molecules increase glucose utilization, reflecting the complex metabolic changes that the mammary gland undergoes throughout lactation.

\section{Remarkable differences in the mammary mRNA} expression profiles of lactating and dried goats The mRNA expression of genes involved in milk protein synthesis is reduced during the dry period

In contrast with the previous comparison, the gene expression profiles of the goat mammary gland are quite different when T1/T2 samples are compared to T3 samples. At T3, we have observed a 5-8 fold downregulation of the genes encoding caseins (the major protein components of milk), while there was also a 9.5-fold reduction in the gene expression of the milk whey LALBA protein, which is essential for the synthesis of lactose [39]. Likewise, the PAEP gene, which encodes the major whey protein $\beta$-lactoglobulin, was down-regulated 4.5 -fold at T3. Similar results have also been obtained in sheep and cattle [10-12, 40]. The reduction in milk protein synthesis can be attributed to the fact that this is an energetically demanding process that is rapidly inhibited in the absence of proper hormonal and nutritional stimulation [41]. In rodents, milk protein synthesis appears to be under the control of the signal transducer and activator of transcription 5 (STAT5) factor [42], but in close similarity to what has been observed in cattle [43], we did not observe a change in the expression of the STAT5A or STAT5B genes. Conversely, there was a 2-fold reduction of the E74 like ETS transcription factor 5 (ELF5), which was also detected in cattle by Bionaz and Loor [43]. The ELF5 gene is regulated by STAT5 and induced by insulin, which might be a major player in the activation of protein synthesis in the bovine mammary gland. Furthermore, and as discussed by Bionaz and Loor [43], one of the factors that probably contributes to the strongly lowered milk protein synthesis during the dry period (T3) is the mRNA downregulation of major amino acid transporters, such as SLC1A1, SLC1A5, SLC7A14 and SLC36A2 [44-46].

The expression of genes involved in carbohydrate and lipid metabolism is downregulated in the dry period

Carbohydrate metabolism is also affected by the ceasing of lactation and, as mentioned before, LALBA, an enzyme necessary for the synthesis of lactose [39], the major sugar in milk, was downregulated at T3. We also observed a decrease in the mRNA expression of the IRS1 gene, which mediates the effects of insulin [47]. Besides being fundamental for the absorption and storage of glucose [48], insulin also has important 
Table 4 List of genes that are differentially expressed and that co-localize with dairy QTL

\begin{tabular}{|c|c|c|c|c|c|c|c|c|c|c|c|}
\hline \multirow[t]{2}{*}{ QTL } & \multirow[t]{2}{*}{ Leading SNP } & \multirow[t]{2}{*}{ Chromosome } & \multirow[t]{2}{*}{ Start } & \multirow[t]{2}{*}{ End } & \multirow[t]{2}{*}{ Gene symbol } & \multicolumn{2}{|c|}{ T1 vs. T2 } & \multicolumn{2}{|c|}{ T1 vs. T3 } & \multicolumn{2}{|c|}{ T2 vs. T3 } \\
\hline & & & & & & $\log _{2} \mathrm{FC}$ & $q$-value & $\log _{2} \mathrm{FC}$ & $q$-value & $\log _{2} \mathrm{FC}$ & $q$-value \\
\hline 1 & rs 268253425 & 2 & $130,227,819$ & $130,232,923$ & MSTN & - & - & -2.17 & 3.30E-05 & -1.66 & $1.14 \mathrm{E}-05$ \\
\hline \multirow[t]{4}{*}{2} & \multirow[t]{4}{*}{ rs268258472 } & 3 & $113,070,996$ & $113,098,602$ & $S H 2 D 1 B$ & - & - & 1.53 & $3.42 \mathrm{E}-04$ & - & - \\
\hline & & 3 & $113,497,530$ & $113,528,836$ & HSD17B7 & - & - & -2.18 & 1.87E-09 & -2.08 & 5.91E-13 \\
\hline & & 3 & $113,589,998$ & $113,598,576$ & CCDC190 & - & - & 2.15 & 3.31E-02 & - & - \\
\hline & & 3 & $113,876,670$ & $113,883,784$ & RGS4 & - & - & -3.45 & 1.10E-03 & -3.25 & 1.73E-04 \\
\hline 4 & rs268251267 & 6 & $15,922,309$ & $15,965,996$ & CFI & - & - & 2.20 & 4.46E-04 & 2.33 & $1.08 \mathrm{E}-05$ \\
\hline \multirow[t]{10}{*}{6} & \multirow[t]{10}{*}{ rs268268356, rs268290907 } & 6 & $84,458,894$ & $84,563,377$ & LOC102185449 & - & - & - & - & -2.04 & $2.62 \mathrm{E}-02$ \\
\hline & & 6 & $84,667,577$ & $84,721,849$ & LOC102186288 & - & - & -4.57 & 7.95E-08 & -3.96 & 5.03E-10 \\
\hline & & 6 & $85,137,434$ & $85,152,951$ & LOC102172432 & - & - & - & - & -3.91 & 3.79E-03 \\
\hline & & 6 & $85,878,003$ & $85,901,026$ & LOC102169846 & - & - & -6.10 & 4.46E-07 & -6.24 & $6.03 \mathrm{E}-06$ \\
\hline & & 6 & $85,978,463$ & $85,995,270$ & CSNIS1 & - & - & -8.17 & $1.31 \mathrm{E}-28$ & -8.03 & $8.28 \mathrm{E}-28$ \\
\hline & & 6 & $86,006,250$ & $86,015,321$ & CSN2 & - & - & -7.24 & 5.06E-15 & -7.23 & $9.68 \mathrm{E}-15$ \\
\hline & & 6 & $86,076,845$ & $86,093,539$ & CSN1S2 & - & - & -8.00 & $1.83 \mathrm{E}-18$ & -8.18 & 1.50E-19 \\
\hline & & 6 & $86,093,738$ & $86,115,903$ & LOC102178810 & - & - & -6.50 & 4.36E-12 & -5.91 & 2.77E-11 \\
\hline & & 6 & $86,197,263$ & $86,211,376$ & CSN3 & - & - & -5.16 & $2.76 \mathrm{E}-11$ & -5.12 & 4.67E-11 \\
\hline & & 6 & $86,427,932$ & $86,443,025$ & AMTN & 1.94 & $2.72 \mathrm{E}-02$ & -2.59 & 4.31E-06 & -4.56 & 4.61E-12 \\
\hline \multirow[t]{3}{*}{7} & \multirow[t]{3}{*}{ rs268250457 } & 11 & $71,885,505$ & $71,909,335$ & GCKR & - & - & -1.96 & 5.40E-09 & - & - \\
\hline & & 11 & $72,204,731$ & $72,208,863$ & TCF23 & - & - & 2.04 & 3.56E-03 & 1.56 & 2.26E-02 \\
\hline & & 11 & $72,818,025$ & $72,863,960$ & $D R C 1$ & - & - & 2.55 & $2.54 \mathrm{E}-07$ & 1.71 & $6.22 \mathrm{E}-04$ \\
\hline \multirow[t]{2}{*}{8} & \multirow[t]{2}{*}{ rs268256521 } & 12 & $67,360,683$ & $67,392,416$ & EBPL & - & - & -2.05 & $6.24 \mathrm{E}-13$ & -2.32 & 7.71E-12 \\
\hline & & 12 & $68,130,994$ & $68,150,636$ & CYSLTR2 & - & - & 1.57 & $1.43 \mathrm{E}-06$ & - & - \\
\hline \multirow[t]{4}{*}{9} & \multirow[t]{4}{*}{ rs268236131 } & 13 & $53,376,787$ & $53,378,322$ & TNFRSF6B & - & - & 1.64 & 6.44E-04 & - & - \\
\hline & & 13 & $53,475,687$ & $53,483,660$ & EEFTA2 & - & - & 2.07 & 2.39E-02 & - & - \\
\hline & & 13 & $53,771,553$ & $53,785,372$ & SLCITA9 & - & - & - & - & -1.94 & 5.05E-10 \\
\hline & & 13 & $54,495,442$ & $54,974,847$ & $\mathrm{CDH} 4$ & - & - & 1.55 & 1.19E-08 & - & - \\
\hline \multirow[t]{2}{*}{11} & \multirow[t]{2}{*}{ rs268255959 } & 14 & $45,768,357$ & $46,228,322$ & KCNB2 & - & - & - & - & -1.63 & 1.45E-02 \\
\hline & & 14 & $46,685,533$ & $46,688,514$ & MSC & - & - & 1.58 & 4.90E-07 & - & - \\
\hline \multirow[t]{2}{*}{13} & \multirow[t]{2}{*}{ rs268290053 } & 15 & $34,071,717$ & $34,073,359$ & LOC102175876 & 4.50 & 3.70E-04 & -4.06 & 9.75E-04 & -8.56 & 7.66E-10 \\
\hline & & 15 & $34,118,282$ & $34,119,849$ & $H B B C$ & - & - & - & - & -3.72 & $6.30 \mathrm{E}-04$ \\
\hline 14 & rs268266747 & 15 & $63,018,327$ & $63,025,893$ & C15H11orf87 & - & - & 4.01 & 7.24E-05 & - & - \\
\hline 15 & rs268236985 & 16 & $39,165,138$ & $39,176,197$ & TNFSF18 & - & - & 1.71 & $1.23 \mathrm{E}-02$ & - & - \\
\hline & & 16 & $40,049,635$ & $40,096,376$ & TNFRSF8 & - & - & 1.53 & 5.39E-04 & - & - \\
\hline 16 & rs268253363 & 16 & $47,058,035$ & $47,175,045$ & AJAP1 & - & - & 2.42 & 2.31E-09 & 1.74 & $3.18 \mathrm{E}-05$ \\
\hline & & 16 & $47,851,111$ & $47,857,057$ & SMIM1 & - & - & -1.53 & 3.69E-14 & -1.52 & $2.29 \mathrm{E}-15$ \\
\hline & & 16 & $47,858,258$ & $47,874,280$ & CCDC27 & - & - & -1.82 & 4.42E-03 & - & - \\
\hline & & 16 & $48,000,776$ & $48,022,801$ & LOC102183348 & - & - & 1.70 & $1.01 \mathrm{E}-03$ & - & - \\
\hline 21 & rs268243170 & 23 & $7,662,629$ & $7,687,922$ & CD83 & - & - & 1.58 & $1.78 \mathrm{E}-06$ & - & - \\
\hline 22 & rs268240589 & 24 & $49,397,175$ & $49,422,345$ & $L I P G$ & - & - & -4.10 & 7.56E-11 & -4.25 & $1.14 \mathrm{E}-11$ \\
\hline & & 24 & $50,316,631$ & $50,490,273$ & MAPK4 & - & - & -3.40 & $3.72 \mathrm{E}-15$ & -2.71 & 2.17E-12 \\
\hline
\end{tabular}

These DE genes were retrieved from an interval of $\pm 988 \mathrm{~kb}$ around leading SNPs (see Methods); Leading SNP: a SNP displaying the most significant association with a given trait; The dash symbol indicates the absence of a significant differential expression; $\log _{2} \mathrm{FC}: \log _{2}$ of the fold change in expression. Start and end indicate the genomic location of the corresponding gene 
effects on the synthesis of milk proteins [49]. While the abundance of SLC2A1 mRNA, one of the main glucose transporters, decreased at T3, we did not observe the same trend for $S L C 2 A 4$, which is another major insulin-responsive glucose transporter [50]. These results agree with data presented by Komatsu et al. [51] who showed that SLC2A1 has a more predominant role than SLC2A4 in the glucose metabolism of the mammary gland during lactation.

The metabolic downregulation of the mammary gland that takes place during dry period has also a major impact on lipid metabolism. At T3, important transcriptional regulators were downregulated, such as PPARA, which is expressed in tissues with a high rate of fatty acid catabolism [52]; ESR2, which can inhibit ligandmediated PPARG-transcriptional activity [53]; LEP, encoding a hormone that stimulates fatty acid oxidation; and INSIG1, encoding a protein that inhibits the proteolytic activation of sterol regulatory element-binding proteins (SREBPs). As mentioned by Bionaz and Loor [54], the case of INSIG1 is quite counterintuitive because the mRNA expression of this gene is upregulated during lactation despite its inhibitory action on SREBPs and lipogenesis. Our interpretation is that the increased expression of INSIG1 during lactation arises from the increased need to fine tune the activity of SREBPs. The pathway enrichment analysis also detected many biochemical routes related to lipid metabolism, including the PPAR signaling pathway. Indeed, PPARG is a master regulator of adipocyte differentiation and lipid and glucose homeostasis [55], and according to Bionaz and Loor [54], PPARG, PPARGC1A, and INSIG1, rather than SREBP1, have a pivotal role in milk fat synthesis in cattle..

\section{Alterations in the expression of genes modulating calcium homeostasis}

In mammals, maternal calcium homeostasis is often challenged by the high calcium demand associated with the lactation process [56]. In the epithelial mammary cell, calcium is stored in and around the Golgi apparatus, and it is secreted into milk in close association with caseins [56]. At T3, the mammary glands of MurcianoGranadina goats displayed reduced mRNA levels of PTHLH, a molecule that favors calcium mobilization through bone resorption during lactation [57], and in parallel, an increased mRNA expression of the FGF23 gene, which inhibits the synthesis of parathyroid hormone [58]. We also observed an upregulation of the TRPV5 and TRPV6 mRNAs, which favor calcium uptake in a broad array of tissues with predominance of kidney [59] and of intestine [60], respectively. From our perspective, the increased expression of these two channels at T3 is quite paradoxical because the abrogation of lactation implies a strong reduction of the calcium demand. A possible explanation is that the increased expression of TRPV5 and TRPV6 genes might contribute to replenish the exhausted mammary calcium pool, but this hypothesis needs to be verified.

\section{Increased mammary expression of genes related with cell death and tissue remodeling during the dry period}

During the dry period (T3), there is an extensive involution, apoptosis and remodeling of the mammary gland that involves the death and replacement of senescent alveolar cells [61], transforming the udder from a milk factory to a quiescent organ [62]. Probably, one of the main cues that triggers this process is milk stasis [63]. The FOS and JUNB genes are upregulated in the mammary gland of Murciano-Granadina goats at T3, a finding that is relevant because they form part of the activator protein 1 (AP-1) dimeric transcription factor. This dimeric transcription factor is probably involved in the initiation or execution of apoptosis after mammary gland stops to milk [64]. We have also detected an increased expression of OSM and its receptor (OSMR), LIF, BCL2L14, IGFBP5 and SOCS3 mRNAs, a set of molecules which are known to promote the death of mammary epithelial cells and to facilitate the involution of the mammary gland [65-68]. Furthermore, metalloproteinases with aggrecanase (ADAMTS4) and cartilage oligomeric matrix protein-cleaving (ADAMTS7) activities [30] were also upregulated at T3, probably because of the extensive tissue remodeling takes place during mammary involution [69]. Indeed, metalloproteinases play a fundamental role not only in the remodeling of the epithelial ductal and vascular networks, but also in the correct synchronization of parenchymal, stromal and extracellular matrix homeostasis.

\section{Complex changes in the expression of genes with immunological functions}

Bacterial infections are seven times more prevalent during the early dry period than during lactation [70], thus increasing the risk to suffer mastitis in the subsequent lactation. The mammary gland can be considered as a temporal mucosal organ [71], and in this regard we have detected a downregulation, at T3, of several molecules that are involved in the synthesis of mucins (MUC1, $M U C 4$ and $M U C 20$ ) or surfactant (ABCA3 and SFTPD) substances. These are two major components of the chemical barrier that protects mucosal surfaces against bacterial infection and biofilm formation. Mucins are large O-linked glycoproteins that form part of the gellike extracellular matrix known as mucus [72]. This is considered to be the first line of defense against pathogens because it can trap bacteria and slow down the diffusion of large viruses and, moreover, it holds 
immunoglobulin A and antimicrobial peptides that facilitate the elimination of pathogenic microorganisms [72]. Surfactant, which is mainly constituted by proteins and lipids, can also stimulate the clearance of microorganisms by increasing the membrane permeability of bacteria and by enhancing phagocytosis featured by cells of the innate immune system [73]. At T3, we have also detected a lowered mammary expression of the BPIFA1, BPIFA2, BPIFA3, BPIFB1and BPIFB4 mRNAs. These molecules also play an essential role in mucosal immunity, being particularly well known the BPIFA1 protein because of its abundance in respiratory secretions, its inhibitory effect on bacterial growth and biofilm formation and its immunomodulatory properties [31]. Our results might suggest that mucous and surfactant substances that protect the mammary epithelium from infectious agents are synthesized at lower levels during the dry period, but in the absence of protein data we cannot draw firm conclusions about this matter.

In parallel, we have detected an increased mRNA expression, at T3, of several complement factors that are an important component of mucosal immunity by favoring immune bacteriolysis, neutralization of viruses, immune adherence, immunoconglutination and phagocytosis [74]. Two $\beta$-defensins (DEFB116 and DEFB126) were also upregulated at T3. Defensins are cationic antimicrobial peptides that bind the negatively charged outer membranes of bacteria and kill them through a variety of mechanisms including pore formation, interference with cell wall synthesis, and prokaryotic membrane depolarization [75]. Interleukin 5, CXCR4 and specific subunits of interleukins 15 and 22 receptors also showed an increase in mRNA expression at T3. Interleukin 5 is a survival factor for B-cells and eosinophils [76], while the chemokine receptor CXCR4 is a major contributor to B-cell homeostasis and humoral immunity [77]. With regard to interleukin 15 , it is a pleiotropic cytokine involved in the establishment of inflammatory and protective immune responses against invading pathogens by regulating the functions of cells belonging to both the innate and adaptive immune systems [78]. In contrast, interleukin 22 promotes the proliferation of epithelial and stromal cells, thus contributing to tissue regeneration, and also to the modulation of host defense at barrier surfaces [79].

\section{About the genetic determinism of dairy traits in Murciano-Granadina goats}

The most significant association that we have detected in our study is that between the chromosome 6 region containing the casein genes (QTL6) and protein percentage. This result is relevant because caseins constitute $\sim 80 \%$ of the total milk protein content [80]. Moreover, we have observed differential expression of the four casein genes when comparing T1/T2 vs. T3. By applying a physiological candidate gene approach, Caravaca et al. [81] found that the CSN3 genotype is significantly associated with casein and protein contents in Murciano-Granadina goats, while the CSN1S1 genotype did not show significant associations with protein, casein, and fat concentrations. In Norwegian goats, Hayes et al. [82] described significant associations between CSN1S1 (protein percentage and fat kilograms) and CSN3 genotypes (fat percentage and protein percentage) and the phenotypic variation of dairy traits. In 2016, Carillier-Jacquin and colleagues [83] reported that CSN1S1 genotypes had a significant effect on milk yield and milk fat and protein contents in French goat breeds. Moreover, a GWAS for dairy traits in Alpine and Saanen goats detected highly significant associations between markers mapping to the casein cluster and milk protein and fat contents [1]. Indeed, we also detected a chromosome-wide significant association between QTL6 and fat percentage. The pleiotropic effects of the casein genotypes on milk protein and fat contents could be due to the fact that, in the mammary epithelial cell, the transport of proteins and lipids is coupled to a certain extent [84].

Another relevant genome-wide significant association was that between QTL1 on chromosome 2 (130.72$131.01 \mathrm{Mb}$ ) and lactose percentage. This region overlaps the NGFI-A binding protein 1 (NAB1) gene, also known as EGR1 binding protein 1 gene. This gene shows an increased expression during mouse lactation and encodes a molecule that binds to the proximal promoter of the galactokinase gene, which is involved in galactose catabolism [85]. We also identified a third genome-wide significant association between a chromosome 17 region (QTL17, $11.20 \mathrm{Mb}$ ) and protein and dry matter percentages. This region closely maps to the T-Box 3 (TBX3) gene, which is highly expressed in luminal cells during early mammary gland initiation by interacting with Wnt and fibroblast growth factor (Fgf) signaling $[86,87]$.

The comparison of the genome-wide and chromosomewide significant associations detected by us vs. those reported by Martin et al. [1] revealed a low level of positional concordance, suggesting the existence of a remarkable level of genetic heterogeneity amongst caprine breeds with regard to the genetic determinism of milk traits. Indeed, in the GWAS carried out by Martin et al. [1] more than $50 \%$ of the associations were exclusively detected in one of the two breeds under analysis (Alpine and Saanen) despite their close genetic relatedness. This finding supports the proposal of using breed-specific reference genomes to increase the accuracy of genomic analyses [88]. Moreover, in humans a large amount of variants occurs at different frequencies in different populations, having 
variable effects on complex traits and producing a substantial level of genetic heterogeneity [89]. Technical and experimental factors related to population size and marker density may also influence statistical power to detect associations [90]. Many of the QTLs detected by us were represented by a single SNP, possibly due to the low LD between nearby markers [91-94]. Finally, only a few genes located within or close to QTLs showed differential expression between T1/T2 and T3, suggesting that the set of DE genes in these two physiological states has a weak correspondence with the set of genes influencing the quantitative variation of milk traits.

\section{Conclusions}

The ceasing of lactation in Murciano-Granadina goats involves the downregulation of the mRNA expression of many genes related to the synthesis, uptake and transportation of proteins, lipids and carbohydrates as well as changes in the mRNA expression of genes involved in the maintenance of calcium homeostasis. We also observed an increased expression of genes modulating cell death and tissue remodeling that probably mediate the involution and regeneration of the mammary gland during the dry period. From an immunological perspective, genes that contribute to the formation of mucous and surfactant barriers are downregulated in the dry period, possibly increasing the risk of infection. However, we have also observed an increase in the mRNA expression of defensin, cytokine and complement genes which should ensure the elicitation of an effective immune response against pathogens. Finally, the results obtained in the GWAS allows us to conclude that the casein genes, which are strongly downregulated during the dry period, are major genetic determinants of the phenotypic variance of milk protein and fat composition traits recorded in Murciano-Granadina goats, thus supporting the use of casein genotypes as a source of information to improve these two phenotypes.

\section{Supplementary information}

Supplementary information accompanies this paper at https://doi.org/10. 1186/s40104-020-00435-4.

Additional file 1: Table S1. Information about the Murciano-Granadina goats sampled in the RNA-Seq experiment.

Additional file 2: Figure S1. Similarity matrix of samples used for detecting differentially expressed genes. $\mathrm{T} 1, \mathrm{~T} 2$ and $\mathrm{T} 3$ correspond to $78.25 \pm 9.29 \mathrm{~d}$ (T1, early lactation), $216.25 \pm 9.29 \mathrm{~d}$ (T2, late lactation) and $285.25 \pm 9.29 \mathrm{~d}(\mathrm{~T} 3$, dry period) after parturition, respectively. The sample T3-22 (red arrow) clustered with T1/T2 samples probably because it was obtained from a goat that was not successfully dried-off at the time of sampling.

Additional file 3: Tables S2-S4. List of differentially expressed genes between the $\mathrm{T} 1$ and $\mathrm{T} 2, \mathrm{~T} 1$ and $\mathrm{T} 3$, and $\mathrm{T} 2$ and $\mathrm{T} 3$ time points.
Additional file 4: Figure S2. Venn diagram depicting the overlaps of differentially expressed genes between pair-wise T1 vs. T2, T1 vs. T3 and $\mathrm{T} 2$ vs. T3 comparisons. T1 and T2 represent early (78.25 $\pm 9.29 \mathrm{~d}$ after parturition) and late $(216.25 \pm 9.29 \mathrm{~d}$ ) lactation, respectively, while T3 ( $285.25 \pm 9.29$ d) corresponds to the dry period.

Additional file 5: Table S5-S6. Pathways and gene ontology (GO) terms enriched in the set of 1,654 differentially expressed genes on the basis of human and goat background gene sets.

Additional file 6: Table S7. Descriptive statistics of seven dairy traits recorded in the first lactation of 822 Murciano-Granadina goats.

Additional file 7: Figure S3. Histograms of the phenotypic values of the percentage of protein (a), fat (b), lactose (c) and dry matter (d), milk yield normalized to $210 \mathrm{~d}$ (e), length of lactation ( $\mathrm{f}$ ), logarithmically transformed somatic cell count $(\mathrm{g})$ recorded in the first lactation of Murciano-Granadina goats. The raw somatic cell count is $\left(\times 10^{3}\right.$ cells $\left./ \mathrm{mL}\right)$ shown in (h).

Additional file 8: Figure S4. Structure of the Murciano-Granadina population employed in the GWAS as assessed by principal component analysis (PCA) based on Goat SNP50 BeadChip genotypes. PC1 and PC2 indicate the principal components 1 and 2, respectively. Values in parentheses reflect the percentage of variance in the data explained by each principal component.

Additional file 9: Figure S5. Linkage disequilibrium (LD) decay in 822 Murciano-Granadina goats with available Goat SNP50 BeadChip genotypes. The scatter plot shows the decline of $r^{2}$ between single nucleotide polymorphisms ( $y$-axis) with distance expressed in bp ( $\mathrm{x}$-axis). The fitting line is depicted in red.

\section{Abbreviations}

DE: Differentially expressed; DMP: Dry matter percentage; FDR: False discovery rate; FP: Fat percentage; GFF: General feature format; GO: Gene ontology; GWAS: Genome-wide association study; LD: Linkage disequilibrium; $\log _{2}$ FC: $\log _{2}$ of the fold-change; LOL: Length of lactation; LP: Lactose percentage; MAF: Minor allele frequency; Mb: Megabase; MY210: Milk yield at 210 days; PCA: Principal component analysis; PP: Protein percentage; QTL: Quantitative trait locus; RNA-Seq: RNA sequencing; SCC: Somatic cell count; SNP: Single nucleotide polymorphism

\section{Acknowledgements}

Many thanks to Manuel Delgado Vico, Emilio Martínez Hurtado, Miguel García García and Teresa Novo Díaz from CAPRIGRAN for carrying out phenotype recording and blood sample collection in Murciano-Granadina goats. We are also indebted to Ramón Costa and all the staff of the Farm and Experimental Field Service of the Universitat Autònoma de Barcelona for their collaboration in the collection of mammary biopsies from goats.

\section{Authors' contributions}

MA, JJ, JVD and VL designed the study. JFA, JVD and AM coordinated all tasks involved in phenotype recording. $V L$ did all DNA extractions. BC and AC assessed DNA quality and carried out the Goat SNP50 BeadChip genotyping tasks. XS, JLRTC, EMS, MA, MGL and DG collected mammary gland biopsies from goats. EMS, MGL and DG did the RNA extractions from the mammary gland samples. DG did the bioinformatic and statistical analyses, with the cooperation of EMS and MGL. MA and DG wrote the first draft of the paper. All authors read and approved the content of the paper.

\section{Funding}

This research was funded by the European Fund for Regional Development/ Ministerio de Ciencia, Innovación y Universidades-Agencia Estatal de Investigación/Project Reference AGL2016-76108-R. We acknowledge the financial support from the Spanish Ministry of Economy and Competitiveness, through the "Severo Ochoa Programme for Centres of Excellence in R\&D" 2016-2019 (SEV-2015-0533), and from the CERCA programme of the Generalitat de Catalunya. Dailu Guan was funded by a PhD fellowship from the China Scholarship Council (CSC). Maria Luigi-Sierra was funded with a PhD fellowship "Formación de Personal Investigador" (BES-C-2017-0024) awarded by the Spanish Ministry of Economy and Competitivity. Emilio Mármol-Sánchez was funded with a PhD fellowship (FPU15/01733) awarded by the Spanish Ministry of Education and Culture (MECD). 


\section{Availability of data and materials}

Goat SNP50 BeadChip genotypes and mammary RNA-Seq data are accessible at Figshare (https://doi.org/10.6084/m9.figshare.11881617) and Sequence Read Archive (SRA) database (PRJNA607923), respectively.

\section{Ethics approval and consent to participate}

The protocol for collecting mammary biopsies was approved by the Ethics Committee on Animal and Human Experimentation of the Universitat Autònoma de Barcelona (procedure code: UAB 3859).

\section{Consent for publication}

Not applicable.

\section{Competing interests}

The authors declare that they have no competing interests.

\section{Author details}

'Centre for Research in Agricultural Genomics (CRAG), CSIC-IRTA-UAB-UB, Universitat Autònoma de Barcelona, 08193 Bellaterra, Spain. ${ }^{2}$ Departamento de Genética, Universidad de Córdoba, 14071 Córdoba, Spain. ${ }^{3}$ Departament de Ciència Animal i dels Aliments, Facultat de Veterinària, Universitat Autònoma de Barcelona, 08193 Bellaterra, Spain. ${ }^{4}$ Asociación Nacional de Criadores de Caprino de Raza Murciano-Granadina (CAPRIGRAN), 18340 Granada, Spain. ${ }^{5}$ Servei de Granges i Camps Experimentals, Universitat Autònoma de Barcelona, 08193 Bellaterra, Spain.

\section{Received: 19 September 2019 Accepted: 17 February 2020}

\section{Published online: 11 March 2020}

\section{References}

1. Martin P, Palhière I, Maroteau C, Bardou P, Canale-Tabet K, Sarry J, et al. A genome scan for milk production traits in dairy goats reveals two new mutations in Dgat1 reducing milk fat content. Sci Rep. 2017;7:1872.

2. Mucha S, Mrode R, Coffey M, Kizilaslan M, Desire S, Conington J. Genomewide association study of conformation and milk yield in mixed-breed dairy goats. J Dairy Sci. 2018:101:2213-25.

3. Sharma A, Lee JS, Dang CG, Sudrajad P, Kim HC, Yeon SH, et al. Stories and challenges of genome wide association studies in livestock - a review. Asian-Austral J Anim Sci. 2015;28:1371-9.

4. Ji Z, Chao T, Zhang C, Liu Z, Hou L, Wang J, et al. Transcriptome analysis of dairy goat mammary gland tissues from different lactation stages. DNA Cell Biol. 2019;38:129-43.

5. Crisà A, Ferrè F, Chillemi G, Moioli B. RNA-sequencing for profiling goat milk transcriptome in colostrum and mature milk. BMC Vet Res. 2016;12:264.

6. Pławińska-Czarnak J, Zarzyńska J, Majewska A, Jank M, Kaba J, Bogdan J, et al. Selected tissues of two polish goat breeds do not differ on genomic level. Anim Sci Pap Rep. 2019:37:53-64.

7. McCabe M, Waters S, Morris D, Kenny D, Lynn D, Creevey C. RNA-Seq analysis of differential gene expression in liver from lactating dairy cows divergent in negative energy balance. BMC Genomics. 2012;13:193.

8. Yang B, Jiao B, Ge W, Zhang X, Wang S, Zhao H, et al. Transcriptome sequencing to detect the potential role of long non-coding RNAs in bovine mammary gland during the dry and lactation period. BMC Genomics. 2018:19:605.

9. Dai WT, Zou YX, White RR, Liu JX, Liu HY. Transcriptomic profiles of the bovine mammary gland during lactation and the dry period. Funct Integr Genomics. 2018;18:125-40.

10. Fang L, Sahana G, Su G, Yu Y, Zhang S, Lund MS, et al. Integrating sequence-based GWAS and RNA-Seq provides novel insights into the genetic basis of mastitis and milk production in dairy cattle. Sci Rep. 2017;7:45560

11. Yang J, Jiang J, Liu X, Wang H, Guo G, Zhang Q, et al. Differential expression of genes in milk of dairy cattle during lactation. Anim Genet. 2016;47:174-80

12. Suárez-Vega A, Gutiérrez-Gil B, Klopp C, Robert-Granie C, Tosser-Klopp G, Arranz $\mathrm{JJ}$. Characterization and comparative analysis of the milk transcriptome in two dairy sheep breeds using RNA sequencing. Sci Rep. 2015:5:18399.

13. Hansen KD, Brenner SE, Dudoit S. Biases in Illumina transcriptome sequencing caused by random hexamer priming. Nucleic Acids Res. 2010;38:e131.
14. Conesa A, Madrigal P, Tarazona S, Gomez-Cabrero D, Cervera A, McPherson A, et al. A survey of best practices for RNA-seq data analysis. Genome Biol. 2016;17:13.

15. Bickhart DM, Rosen BD, Koren S, Sayre BL, Hastie AR, Chan S, et al. Singlemolecule sequencing and chromatin conformation capture enable de novo reference assembly of the domestic goat genome. Nat Genet. 2017:49:643-50.

16. Kim D, Landmead B, Salzberg SL. HISAT: a fast spliced aligner with low memory requirements. Nat Methods. 2015;12:357-60.

17. Pertea M, Kim D, Pertea GM, Leek JT, Salzberg SL. Transcript-level expression analysis of RNA-Seq experiments with HISAT, StringTie and Ballgown. Nat Protoc. 2016;11:1650-67.

18. Liao Y, Smyth GK, Shi W. featureCounts: an efficient general purpose program for assigning sequence reads to genomic features. Bioinformatics. 2014;30:923-30.

19. Love MI, Huber W, Anders S. Moderated estimation of fold change and dispersion for RNA-Seq data with DESeq2. Genome Biol. 2014;15:550.

20. Benjamini $Y$, Hochberg Y. Controlling the false discovery rate: a practical and powerful approach to multiple testing. J Royal Stat Soc B. 1995;57:289-300

21. Huang DW, Sherman BT, Lempicki RA. Systematic and integrative analysis of large gene lists using DAVID bioinformatics resources. Nat Protoc 2008;4:44-57.

22. Huang DW, Sherman BT, Lempicki RA. Bioinformatics enrichment tools: paths toward the comprehensive functional analysis of large gene lists. Nucleic Acids Res. 2009:37:1-13.

23. Miller SA, Dykes DD, Polesky HF. A simple salting out procedure for extracting DNA from human nucleated cells. Nucleic Acids Res. 1988;16:1215

24. Tosser-Klopp G, Bardou P, Bouchez O, Cabau C, Crooijmans R, Dong Y, et al. Design and characterization of a 52K SNP Chip for goats. PLoS One. 2014;9:e86227.

25. Price AL, Patterson NJ, Plenge RM, Weinblatt ME, Shadick NA, Reich D. Principal components analysis corrects for stratification in genome-wide association studies. Nat Genet. 2006;38:904-9.

26. Patterson N, Price AL, Reich D. Population structure and eigenanalysis. PLoS Genet. 2006;2:e190.

27. Zhou X, Stephens M. Genome-wide efficient mixed-model analysis for association studies. Nat Genet. 2012;44:821-4.

28. Quinlan AR, Hall IM. BEDTools: a flexible suite of utilities for comparing genomic features. Bioinformatics. 2010;26:841-2.

29. Purcell S, Neale B, Todd-Brown K, Thomas L, Ferreira MAR, Bender D, et al. PLINK: a tool set for whole-genome association and population-based linkage analyses. Am J Hum Genet. 2007:81:559-75.

30. Kelwick R, Desanlis I, Wheeler GN, Edwards DR. The ADAMTS (a Disintegrin and metalloproteinase with Thrombospondin motifs) family. Genome Biol. 2015:16:113.

31. Britto CJ, Cohn L. Bactericidal/permeability-increasing protein foldcontaining family member A1 in airway host protection and respiratory disease. Am J Respir Cell Mol Biol. 2015;52:525-34.

32. Kinugasa T, Sakaguchi T, Gu X, Reinecker HC. Claudins regulate the intestinal barrier in response to immune mediators. Gastroenterology. 2000;118:1001-11.

33. Anantamongkol U, Charoenphandhu N, Wongdee K, Teerapornpuntakit J, Suthiphongchai T, Prapong S, et al. Transcriptome analysis of mammary tissues reveals complex patterns of transporter gene expression during pregnancy and lactation. Cell Biol Int. 2010;34:67-74.

34. Robinson GW, Hennighausen L. Inhibins and activins regulate mammary epithelial cell differentiation through mesenchymal-epithelial interactions. Development. 1997;124:2701-8.

35. Jones PL, Boudreau N, Myers CA, Erickson HP, Bissell MJ. Tenascin-C inhibits extracellular matrix-dependent gene expression in mammary epithelial cells. Localization of active regions using recombinant tenascin fragments. J Cell Sci. 1995:108:519-27.

36. van Hekken DL, Eigel WN. Distribution of the lysosomal enzyme aryl sulfatase in murine mammary tissue through pregnancy, lactation, and involution. J Dairy Sci. 1990;73:2318-26.

37. Maksimovic J, Sharp JA, Nicholas KR, Cocks BG, Savin K. Conservation of the ST6Gal I gene and its expression in the mammary gland. Glycobiology. 2010;21:467-81.

38. Bennett EP, Mandel U, Clausen H, Gerken TA, Fritz TA, Tabak LA. Control of mucin-type O-glycosylation: a classification of the polypeptide GalNActransferase gene family. Glycobiology. 2011;22:736-56. 
39. Osorio JS, Lohakare J, Bionaz M. Biosynthesis of milk fat, protein, and lactose: roles of transcriptional and posttranscriptional regulation. Physio Genomics. 2016:48:231-56.

40. Dado-Senn B, Skibiel AL, Fabris TF, Zhang Y, Dahl GE, Peñagaricano $F$, et al. RNA-Seq reveals novel genes and pathways involved in bovine mammary involution during the dry period and under environmental heat stress. Sci Rep. 2018:8:11069.

41. Bionaz $M$, Hurley $W$, Loor J. Milk protein synthesis in the lactating mammary gland: insights from transcriptomics analyses. In: Hurley WL, editor. Milk Protein. London: IntechOpen; 2012. https://doi.org/10.5772/46054.

42. Wakao H, Gouilleux F, Groner B. Mammary-gland factor (Mgf) is a novel member of the cytokine regulated transcription factor gene family and confers the prolactin response. EMBO J. 1994;13:2182-91.

43. Bionaz M, Loor JJ. Gene networks driving bovine mammary protein synthesis during the lactation cycle. Bioinform Biol Insights. 2011:5:83-98.

44. Bailey CG, Ryan RM, Thoeng AD, Ng C, King K, Vanslambrouck JM, et al. Loss-of-function mutations in the glutamate transporter SLC1A1 cause human dicarboxylic aminoaciduria. J Clin Invest. 2011;121:446-53.

45. Closs El, Boissel JP, Habermeier A, Rotmann A. Structure and function of cationic amino acid transporters (CATs). J Membr Biol. 2006;213:67-77.

46. Scalise M, Pochini L, Console L, Losso MA, Indiveri C. The human SLC1A5 (ASCT2) amino acid transporter: from function to structure and role in cell biology. Front Cell Dev Biol. 2018;6:96.

47. Boucher J, Kleinridders A, Kahn CR. Insulin receptor signaling in normal and insulin-resistant states. Cold Spring Harb Perspect Biol. 2014;6:a009191.

48. Bequette BJ, Kyle CE, Crompton LA, Buchan V, Hanigan MD. Insulin regulates milk production and mammary gland and hind-leg amino acid fluxes and blood flow in lactating goats. J Dairy Sci. 2001;84:241-55.

49. Menzies KK, Lefèvre C, Macmillan KL, Nicholas KR. Insulin regulates milk protein synthesis at multiple levels in the bovine mammary gland. Funct Integr Genomics. 2009;9:197-217.

50. Huang S, Czech MP. The GLUT4 glucose transporter. Cell Metab. 2007:5:237-52.

51. Komatsu T, Itoh F, Kushibiki S, Hodate K. Changes in gene expression of glucose transporters in lactating and nonlactating cows. J Anim Sci. 2005:83:557-64.

52. Yoon M. The role of PPARa in lipid metabolism and obesity: focusing on the effects of estrogen on PPARa actions. Pharm Res. 2009;60:151-9.

53. Foryst-Ludwig A, Clemenz M, Hohmann S, Hartge M, Sprang C, Frost N, et al. Metabolic actions of estrogen receptor Beta (ERB) are mediated by a negative cross-talk with PPARY. PLoS Genet. 2008:4:e1000108.

54. Bionaz $\mathrm{M}$, Loor JJ. Gene networks driving bovine milk fat synthesis during the lactation cycle. BMC Genomics. 2008;9:366.

55. Ahmadian M, Suh JM, Hah N, Liddle C, Atkins AR, Downes M, et al. PPARy signaling and metabolism: the good, the bad and the future. Nat Med. 2013:19:557-66.

56. Horst RL, Goff JP, Reinhardt TA. Calcium and vitamin D metabolism during lactation. J Mammary Gland Biol Neoplasia. 1997;2:253-63.

57. Wysolmerski JJ. Parathyroid hormone-related protein: an update. J Clin Endocrinol Metab. 2012:97:2947-56

58. Lanske B, Razzaque MS. Molecular interactions of FGF23 and PTH in phosphate regulation. Kidney Int. 2014;86:1072-4.

59. Mensenkamp AR, Hoenderop JGJ, Bindels RJM. TRPV5, the gateway to $\mathrm{Ca}^{2+}$ homeostasis. In: Flockerzi V, Nilius B, editors. Transient Receptor Potential (TRP) channels. Berlin: Springer Berlin Heidelberg; 2007. p. 207-20.

60. Peng JB, Suzuki Y, Gyimesi G, Hediger MA. TRPV5 and TRPV6 calciumselective channels. In: Kozak JA, Putney Jr JW, editors. Calcium entry channels in non-excitable cells. Boca Raton (FL): CRC Press/Taylor \& Francis; 2018. https://doi.org/10.1201/9781315152592-13.

61. Yu TC, Chang CJ, Ho CH, Peh HC, Chen SE, Liu WB, et al. Modifications of the defense and remodeling functionalities of bovine neutrophils inside the mammary gland of milk stasis cows received a commercial dry-cow treatment. Vet Immunol Immunopathol. 2011;144:210-9.

62. Watson CJ. Involution: apoptosis and tissue remodelling that convert the mammary gland from milk factory to a quiescent organ. Breast Cancer Res. 2006:8:203.

63. Stanford JC, Cook RS. Apoptosis and clearance of the secretory mammary epithelium. In: Rudner J, editor. Apoptosis. London: IntechOpen; 2013. https://doi.org/10.5772/52160.

64. Marti A, Lazar H, Ritter P, Jaggi R. Transcription factor activities and gene expression during mouse mammary gland involution. J Mammary Gland Biol Neoplasia. 1999:4:145-52.
65. Le Provost F, Miyoshi K, Vilotte J-L, Bierie B, Robinson GW, Hennighausen L. SOCS3 promotes apoptosis of mammary differentiated cells. Biochem Biophys Res Commun. 2005;338:1696-701.

66. Schere-Levy C, Buggiano V, Quaglino A, Gattelli A, Cirio MC, Piazzon I, et al. Leukemia inhibitory factor induces apoptosis of the mammary epithelial cells and participates in mouse mammary gland involution. Exp Cell Res. 2003;282:35-47.

67. Marshman E, Green KA, Flint DJ, White A, Streuli CH, Westwood M. Insulinlike growth factor binding protein 5 and apoptosis in mammary epithelial cells. J Cell Sci. 2003;116:675-82.

68. Tiffen PG, Omidvar N, Marquez-Almuina N, Croston D, Watson CJ, Clarkson RWE. A dual role for oncostatin $\mathrm{M}$ signaling in the differentiation and death of mammary epithelial cells in vivo. Mol Endocrinol. 2008:22:2677-88.

69. Khokha R, Werb Z. Mammary gland reprogramming: metalloproteinases couple form with function. Cold Spring Harb Perspect Biol. 2011;3: a004333.

70. Leelahapongsathon K, Piroon T, Chaisri W, Suriyasathaporn W. Factors in dry period associated with intramammary infection and subsequent clinical mastitis in early postpartum cows. Asian-Austral J Anim Sci. 2016:29:580-5.

71. Betts CB, Pennock ND, Caruso BP, Ruffell B, Borges VF, Schedin P. Mucosal immunity in the female murine mammary gland. J Immunol. 2018;201:734-46.

72. Hasnain SZ, Gallagher AL, Grencis RK, Thornton DJ. A new role for mucins in immunity: insights from gastrointestinal nematode infection. Int J Biochem Cell Biol. 2013;45:364-74

73. Han S, Mallampalli RK. The role of surfactant in lung disease and host defense against pulmonary infections. Ann Am Thorac Soc. 2015;12:765-74.

74. Rainard P. The complement in milk and defense of the bovine mammary gland against infections. Vet Res. 2003;34:647-70.

75. Meade KG, O'Farrelly C. $\beta$-Defensins: farming the microbiome for homeostasis and health. Front Immunol. 2019:9:3072.

76. Takatsu K. Interleukin-5 and IL-5 receptor in health and diseases. Proc Jpn Acad Ser B Phys Biol Sci. 2011;87:463-85.

77. Nie Y, Waite J, Brewer F, Sunshine MJ, Littman DR, Zou YR. The role of CXCR4 in maintaining peripheral B cell compartments and humoral immunity. J Exp Med. 2004;200:1145-56.

78. Perera P-Y, Lichy JH, Waldmann TA, Perera LP. The role of interleukin-15 in inflammation and immune responses to infection: implications for its therapeutic use. Microbes Infect. 2012;14:247-61.

79. Dudakov JA, Hanash AM, van den Brink MRM. Interleukin-22: immunobiology and pathology. Annu Rev Immunol. 2015;33:747-85.

80. Corredig M, Nair PK, Li Y, Eshpari H, Zhao Z. Invited review: understanding the behavior of caseins in milk concentrates. J Dairy Sci. 2019;102:4772-82.

81. Caravaca F, Carrizosa J, Urrutia B, Baena F, Jordana J, Amills M, et al. Short

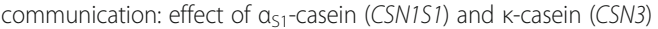
genotypes on milk composition in Murciano-Granadina goats. J Dairy Sci. 2009:92:2960-4.

82. Hayes B, Hagesæther N, Ådnøy T, Pellerud G, Berg PR, Lien S. Effects on production traits of haplotypes among casein genes in Norwegian goats and evidence for a site of preferential recombination. Genetics. 2006;174: 455-64.

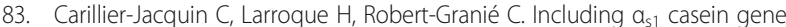
information in genomic evaluations of French dairy goats. Genet Sel Evol. 2016;48:54.

84. Ollivier-Bousquet M. Milk lipid and protein traffic in mammary epithelial cells: joint and independent pathways. Reprod Nutr Dev. 2002:42:149-62.

85. Yang F, Agulian T, Sudati JE, Rhoads DB, Levitsky LL. Developmental regulation of galactokinase in suckling mouse liver by the Egr-1 transcription factor. Pediatr Res. 2004;55:822-9.

86. Platonova N, Scotti M, Babich P, Bertoli G, Mento E, Meneghini V, et al. TBX3, the gene mutated in ulnar-mammary syndrome, promotes growth of mammary epithelial cells via repression of p19ARF, independently of p53. Cell Tissue Res. 2007;328:301-16.

87. Eblaghie MC, Song S-J, Kim J-Y, Akita K, Tickle C, Jung H-S. Interactions between FGF and Wht signals and Tbx3 gene expression in mammary gland initiation in mouse embryos. J Anat. 2004;205:1-13.

88. Czech B, Fraszczak M, Mielczarek M, Szyda J. Identification and annotation of breed-specific single nucleotide polymorphisms in Bos taurus genomes. PLoS One. 2018:13:e0198419.

89. Wojcik GL, Graff M, Nishimura KK, Tao R, Haessler J, Gignoux CR, et al. Genetic analyses of diverse populations improves discovery for complex traits. Nature. 2019;570:514-8. 
90. Tam V, Patel N, Turcotte M, Bossé Y, Paré G, Meyre D. Benefits and limitations of genome-wide association studies. Nat Rev Genet. 2019;20: 467-84.

91. Lashmar SF, Visser C, Ev M-K. SNP-based genetic diversity of South African commercial dairy and fiber goat breeds. Small Rumin Res. 2016;136:65-71.

92. Michailidou S, Tsangaris GT, Tzora A, Skoufos I, Banos G, Argiriou A, et al. Analysis of genome-wide DNA arrays reveals the genomic population structure and diversity in autochthonous Greek goat breeds. PLoS One. 2019:14:e226179.

93. Visscher PM, Wray NR, Zhang Q, Sklar P, McCarthy MI, Brown MA, et al. 10 years of GWAS discovery: biology, function, and translation. Am J Hum Genet. 2017;101:5-22.

94. Schaid DJ, Chen W, Larson NB. From genome-wide associations to candidate causal variants by statistical fine-mapping. Nat Rev Genet. 2018; 19:491-504

Ready to submit your research? Choose BMC and benefit from:

- fast, convenient online submission

- thorough peer review by experienced researchers in your field

- rapid publication on acceptance

- support for research data, including large and complex data types

- gold Open Access which fosters wider collaboration and increased citations

- maximum visibility for your research: over $100 \mathrm{M}$ website views per year

At BMC, research is always in progress.

Learn more biomedcentral.com/submissions 